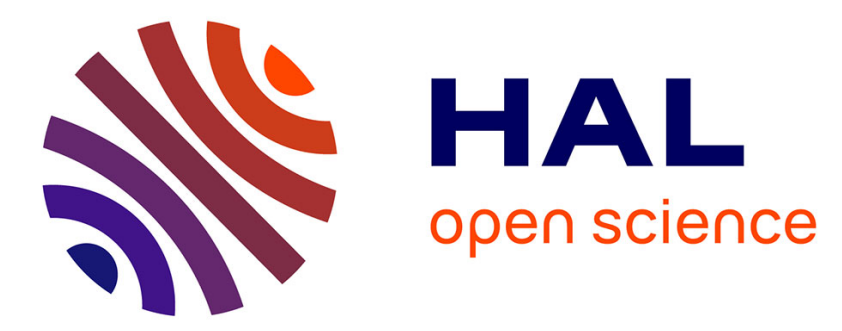

\title{
A coupled nanoindentation/SEM-EDS study on low water/cement ratio Portland cement paste: Evidence for $\mathrm{C}-\mathrm{S}-\mathrm{H} / \mathrm{Ca}(\mathrm{OH}) 2$ nanocomposites
}

Jeffrey J. Chen, Luca Sorelli, Matthieu Vandamme, Franz-Josef Ulm, Gilles

Chanvillard

\section{To cite this version:}

Jeffrey J. Chen, Luca Sorelli, Matthieu Vandamme, Franz-Josef Ulm, Gilles Chanvillard. A coupled nanoindentation/SEM-EDS study on low water/cement ratio Portland cement paste: Evidence for C$\mathrm{S}-\mathrm{H} / \mathrm{Ca}(\mathrm{OH}) 2$ nanocomposites. Journal of the American Ceramic Society, 2010, 93 (5), pp.1484-1493. 10.1111/j.1551-2916.2009.03599.x . hal-00555495

\section{HAL Id: hal-00555495 https://hal.science/hal-00555495}

Submitted on 22 Aug 2011

HAL is a multi-disciplinary open access archive for the deposit and dissemination of scientific research documents, whether they are published or not. The documents may come from teaching and research institutions in France or abroad, or from public or private research centers.
L'archive ouverte pluridisciplinaire HAL, est destinée au dépôt et à la diffusion de documents scientifiques de niveau recherche, publiés ou non, émanant des établissements d'enseignement et de recherche français ou étrangers, des laboratoires publics ou privés. 


\title{
A coupled nanoindentation/SEM-EDS study on low water/cement ratio Portland cement paste: \\ Evidence for $\mathrm{C}-\mathrm{S}-\mathrm{H} / \mathrm{CH}$ nanocomposites
}

Jeffrey J. Chen ${ }^{a^{*}}$, Luca Sorelli ${ }^{a^{\dagger}}$, Matthieu Vandamme ${ }^{b \ddagger}$, Franz-Josef Ulm ${ }^{b}$, and Gilles Chanvillard ${ }^{a}$

${ }^{a}$ Lafarge Centre de Recherche, 38291 Saint Quentin Fallavier, France

${ }^{b}$ MIT, Dept. Civil and Environ. Eng., Cambridge, MA, 02139

\begin{abstract}
A low water/cement ratio $(w / c=0.20)$ hydrated Portland cement paste was analyzed by grid-indentation coupled with ex-situ SEM-EDS analysis at each indentation point. Since finite element and Monte-Carlo simulations showed that the microvolumes probed by each method are of comparable size (approximately $2 \mu \mathrm{m})$, the mechanical information provided by nanoindentation was directly comparable to the chemical information provided by SEM-EDS. This coupled approach permitted the opportunity to determine whether the local indentation response was a result of a single- or multi-phase response - the latter being shown predominant in the highly concentrated $w / c=0.20$ hydrated cement paste. Results indicate that, in the selected microvolumes where $\mathrm{C}-\mathrm{S}-\mathrm{H}$ and nanoscale $\mathrm{Ca}(\mathrm{OH})_{2}(\mathrm{CH})$ are present, increasing fractions of $\mathrm{CH}$ increase the local indentation modulus (and hardness), yielding values above those reported for highdensity (HD) $\mathrm{C}-\mathrm{S}-\mathrm{H}$. Micromechanical analyses show that $\mathrm{C}-\mathrm{S}-\mathrm{H}$ and $\mathrm{CH}$ are associated, not merely as a simple bi-phase mixture, but as an intimate nanocomposite where nanoscale $\mathrm{CH}$ reinforces $\mathrm{C}-\mathrm{S}-\mathrm{H}$ by partially filling the latter's gel pores. The paper discusses the mechanism of forming the $\mathrm{C}-\mathrm{S}-\mathrm{H} / \mathrm{CH}$ nanocomposite, as well as the impact of nanocomposites on various macroscopic properties of concrete (e.g., shrinkage, expansion). On a general level, this study illustrates how a coupled nanoindentation/X-ray microanalysis/micromechanics approach can obtain otherwise inaccessible information on the
\end{abstract}

\footnotetext{
* Corresponding author: jeffrey.chen@lafarge.com

† Current address: Université Laval, Québec, Québec G1V 0A6, Canada

$\$$ Current address: Ecole des Ponts - UR Navier, 77420 Champs-sur-Marne, France
} 
nanomechanical properties of highly heterogeneous composites with intermixing at length scales smaller than the stress field in a nanoindentation experiment.

\section{Introduction}

The principle binding phase of concrete is a poorly-crystalline calcium silicate hydrate gel, denoted as C$\mathrm{S}-\mathrm{H} .{ }^{1}$ At a scale of tens of nanometers, $\mathrm{C}-\mathrm{S}-\mathrm{H}$ possesses an internal pore structure comprised of pores approximately several nanometers across. ${ }^{2}$ This fine porous structure, akin to that of a colloidal gel, creates a high interfacial surface area between solid and liquid phases, which subsequently gives rise to the characteristic poro-viscoelastic response of concrete to mechanical loading and drying, ${ }^{3-5}$ as well as to the generation of crystallization pressure from the growth of ice or salts in small pores. ${ }^{6-8}$ These mechanisms are critical in determining the long-term performance of concrete structures.

In a classic study, Powers ${ }^{9}$ showed that the porosity of $\mathrm{C}-\mathrm{S}-\mathrm{H}$ gel was nearly constant over a wide range of cement compositions and water/cement $(w / c)$ mass ratios. Numerous models ${ }^{10-13}$ of $\mathrm{C}-\mathrm{S}-\mathrm{H}$ have attempted to explain this intrinsic and intriguing nature of the $\mathrm{C}-\mathrm{S}-\mathrm{H}$ pore structure. Jennings has proposed $^{13}$ and recently extended ${ }^{14}$ a comprehensive model, which envisions $\mathrm{C}-\mathrm{S}-\mathrm{H}$ gel as a particulate colloid comprised of 4-5-nm elementary globules that pack into fractal structures with two preferential morphologies. The low-density (LD) C-S-H structure is believed to have an average packing density of 0.64, the high-density (HD) $\mathrm{C}-\mathrm{S}-\mathrm{H}$ a value of 0.75 ; these values suggest packing configurations that approach the theoretical limits for the maximally random jammed state ${ }^{15}$ and the hexagonal-close packed arrangement of spheres ${ }^{16}$, respectively. Through an independent experimental route, grid indentation studies ${ }^{17}$ on cement paste have concluded nearly identical values for the packing densities of LD and HD C-S-H. From a physical perspective, LD C-S-H forms preferentially in the capillary space (i.e., thus forming outer-product (OP) hydrates) where crystal growth can occur in a relatively unimpeded manner. In contrast, $\mathrm{HD} \mathrm{C}-\mathrm{S}-\mathrm{H}$ forms in more confined regions located within the original boundaries of the cement (i.e., thus forming inner product (IP) hydrates) or within confined capillary spaces. 
Recent nanoindentation studies by Vandamme and $\mathrm{Ulm}^{18,64}$ on low $w / c$ ratio pastes have illustrated an additional complexity to the above model of $\mathrm{C}-\mathrm{S}-\mathrm{H}$. Upon decreasing the $w / c$ ratio of a series of cement pastes from 0.40 to 0.15 , it was shown that, in addition to the increase in $\mathrm{HD} \mathrm{C}-\mathrm{S}-\mathrm{H}$ at the expense of $\mathrm{LD}$ $\mathrm{C}-\mathrm{S}-\mathrm{H}$ (a trend originally proposed by Tennis and Jennings ${ }^{19}$ ), there is the formation of a mechanical phase with elevated indentation modulus, $M$, and indentation hardness, $H$. The $(M, H)$ values for this socalled "ultra-high density" (UHD) phase were reported as $(47.2 \mathrm{GPa}, 1.6 \mathrm{GPa})^{18}$, compared to $(29.1 \pm 4.0$ $\mathrm{GPa}, 0.83 \pm 0.18 \mathrm{GPa})^{16}$ and $(18.2 \pm 4.2,0.45 \pm 0.14 \mathrm{GPa})^{16}$ for HD and LD C-S-H, respectively. Under the assumption that the UHD phase is comprised of the same elementary $\mathrm{C}-\mathrm{S}-\mathrm{H}$ particle as in LD and HD C-S-H, it was proposed that the elevated mechanical properties of this UHD phase was achieved by a random packing of 2 particle classes, yielding a packing density of $\eta=\eta_{1}+\left(1-\eta_{1}\right) \eta_{2}=0.87$ (assuming $\left.\eta_{1}=\eta_{2}=0.64\right)$

The motivation for this study was to determine the chemical nature of the UHD phase identified by grid indentation. This method has been reviewed elsewhere, ${ }^{20,21}$ so only points pertinent to the current study are discussed below. Grid indentation involves the application of a large array of nanoindentation experiments, each with a characteristic indentation depth, $h$, which solicits a mechanical response from a subsurface microvolume (Figure 1). From the simultaneous measurement of indentation load and displacement, $M$ and $H$ can be computed ${ }^{22}$ at each point. When applying this procedure over a large array of indents, a deconvolution method ${ }^{17,20}$ can be applied to the resulting cumulative frequency $M$ and $H$ histograms to identify the mean $M, H$ values, as well as the respective volume fractions for each "mechanical" phase in the system. In order to directly correlate the mechanical phase with a unique chemical phase, the size of the probed microvolume must be sufficiently smaller than the characteristic size, $D$, of the chemical phase of interest (Figure 1a): calculations ${ }^{20}$ indicate that $h_{\max }$ must be less than approximately $D / 10$ for this condition to hold. If, on the other hand, $h_{\max }$ is greater than approximately $D / 10$, then a composite mechanical response will inevitably be observed (Figure 1b). Due to the roughness of a polished cement paste surface, ${ }^{23}$ indentation depths in the hydrated cement paste are generally limited 
to values of $h_{\max } \approx 200 \mathrm{~nm}$, which correspond to probed microvolumes with linear depths of approximately $2 \mu \mathrm{m}$. Since SEM-EDS ${ }^{24}$ and $\mathrm{TEM}^{25}$ studies often show intermixing of hydrated mineral phases in a hydrated cement paste on a submicron scale, the mechanical phases detected in the probability density plots of $M$ and $H$ are potentially a composite response of multiple phases. In favour of this conjecture are recent results from small-angle neutron scattering measurements that provide evidence for nanoscale $\mathrm{Ca}(\mathrm{OH})_{2}(\mathrm{CH})$ in hydrated cement paste. ${ }^{26}$

The specific goals of the experimental study were to develop a methodology that could 1) determine if a local composite mechanical response was present, and 2) if so, quantify the influence of the individual chemical phases on this composite mechanical response. Ex-situ SEM-EDS spot analyses were therefore performed at each nanoindentation point in the grid of points on the low $w / c=0.20$ cement paste. Since the microvolumes probed in each technique are similar (Section 3.1), the chemical information from SEM-EDS was directly related to the mechanical information obtained by nanoindentation. While this general approach has been followed in another $\operatorname{study}^{27}$, the sizes of the microvolumes probed by SEMEDS and nanoindentation in the study were of significantly different magnitude, and, as a result, the results could only be compared in a qualitative fashion. Results in the current study, coupled with micromechanical analysis, demonstrate that the UHD phase is, in fact, an intimate nanocomposite of HD $\mathrm{C}-\mathrm{S}-\mathrm{H}$ and nanoscale $\mathrm{CH}$ that reside in the gel pores of $\mathrm{C}-\mathrm{S}-\mathrm{H}$. On a general level, the study illustrates the utility of coupling SEM-EDS, nanoindentation, and micromechanics to study mechanical behavior in highly heterogeneous materials at the nanometer scale.

\section{Experimental procedure}

\subsection{Materials}

The cement paste was prepared with a Type 1 Portland cement from Le Teil, France with deionized water at a $w / c$ ratio of 0.20 . Rietveld XRD analysis showed the cement rich in calcium silicates (alite, $71.1 \%$; belite, $15.0 \%$ ), moderately rich in the ferrite phase (7.0\%), and low in the aluminate phase (1.2\%). XRF showed the following oxide composition: $\mathrm{CaO}, 67.2 \% ; \mathrm{SiO}_{2}, 22.1 \% ; \mathrm{Al}_{2} \mathrm{O}_{3}, 3.1 \% ; \mathrm{Fe}_{2} \mathrm{O}_{3}, 2.5 \% ; \mathrm{SO}_{3}$, 
2.1\%. loss-on-ignition, $1.7 \%$. The blaine specific surface area of the cement was measured as $2,940 \mathrm{~cm}^{2}$ $\mathrm{g}^{-1}$.

The cement paste sample was cast and cured sealed at $20^{\circ} \mathrm{C}$ in plastic cylinders of $10 \mathrm{~mm}$ internal diameter and several centimeters in length. The predominance of the calcium silicate phases (together representing over $85 \%$ of the cement), combined with the low reactivity of the ferrite phase, caused the hydrated cement paste to be comprised largely of $\mathrm{C}-\mathrm{S}-\mathrm{H}$ and $\mathrm{CH}$. The composition of the alite and belite phases were measured by SEM-EDS (Section 2.3) as $\mathrm{Ca}_{2.93} \mathrm{Si}_{0.96} \mathrm{Al}_{0.06} \mathrm{Fe}_{0.01} \mathrm{Mg}_{0.05} \mathrm{~S}_{0.01} \mathrm{O}_{5}(\mathrm{Ca} / \mathrm{Si}=3.07)$ and $\mathrm{Ca}_{1.96} \mathrm{Si}_{0.86} \mathrm{Al}_{0.08} \mathrm{Fe}_{0.02} \mathrm{Mg}_{0.02} \mathrm{~S}_{0.05} \mathrm{O}_{5}(\mathrm{Ca} / \mathrm{Si}=2.28)$, respectively. After approximately 1 year of sealed hydration, a polished cross section of the sample was prepared as described below.

\subsection{Nanoindentation}

A nanoindentation test consists of maintaining contact between a solid and a rigid indenter (typically diamond), while simultaneously measuring changes in the applied load, $P$, and the penetration depth, $h{ }^{28}$ The properties extracted from a $P-h$ curve are the indentation modulus, $M$ and indentation hardness, $H:^{22}$

$$
M=\frac{\operatorname{def}}{2} \frac{\sqrt{\pi}}{\sqrt{A_{C}}} ; \quad H=\frac{{ }^{d e f}}{P_{\max }}
$$

where $S$ is the unloading indentation stiffness, and $A_{C}$ is the projected contact area (Figure 1). The latter is estimated from the maximum penetration depth, $h_{\max }$, using the Oliver and Pharr method. ${ }^{22}$ For a homogeneous isotropic linear elastic material, $M$ reduces to the plane-stress elastic modulus $M=E /(1-v)^{2}$ where $E$ is the Young's modulus and $v$ is the Poisson's ratio of the indented material. Similarly, the hardness $H$ can be related to the indenter cone angle and to the strength properties of a cohesive-frictional material by means of limit analysis. ${ }^{29,30}$ Recently, the application of the technique has been extended to heterogeneous materials such as cementitious materials, bones, and shales. ${ }^{17}$

In this work, nanoindentation was performed over a grid of $20 \times 12$ points, evenly spaced by $20 \mu \mathrm{m}$. During each test, the load was linearly increased up to a maximum load of $4 \mathrm{mN}$ in 10 seconds, kept constant for 5 seconds, and linearly decreased in 10 seconds. The mean measured maximum indentation depth $h_{\max }$ was approximately $310 \mathrm{~nm}$. The Berkovich indenter with a three-sided pyramidal shape and a 
semi-vertical angle of $65.3^{\circ}$ was chosen to minimize the pile-up phenomena. A quartz standard of known mechanical properties was used to calibrate the contact area function of the indenter. ${ }^{22}$

To prepare the flat surface required for nanoindentation, the sample was fixed on a steel support, coarsely ground with Si-C paper, then polished on a lapping wheel impregnated with $1-\mu \mathrm{m}$ diamond paste $^{23}$. The sample was subsequently cleaned with $n$-decane in an ultrasonic bath for five minutes. Since the sample was not supported with epoxy as in conventional methods to prepare polished samples for SEM analyses, some surface defects were observed (e.g., cracks, pop-outs). These points were excluded from the coupled nanoindentation/SEM-EDS analysis. No evidence for pore filling by surface detritus ${ }^{31}$ was observed.

\subsection{SEM-EDS BSE/SE imaging}

Energy dispersive X-ray spectra (EDS) were collected on a JEOL 840 SEM on the same specimen tested by the grid indentation method. Spot analyses were taken just adjacent to the indentation imprint to avoid errors introduced by the local surface roughness. Analyses were conducted with an accelerating voltage of $15 \mathrm{kV}$, with a beam current of $1 \mathrm{nA}$ (measured with a Faraday cup), and with a $15 \mathrm{~mm}$ working distance. Calibrations were made on a range of standard specimens, including $\mathrm{Ca}_{2} \mathrm{SiO}_{4}, \mathrm{Ca}_{3} \mathrm{Al}_{2} \mathrm{O}_{6}, \mathrm{Fe}_{2} \mathrm{O}_{3}, \mathrm{MgO}$, $\mathrm{CaSO}_{4},(\mathrm{~K}, \mathrm{Na})(\mathrm{Si}, \mathrm{Al})_{4} \mathrm{O}_{8}, \mathrm{InP}, \mathrm{Mn}$, and Ti. $\mathrm{Ca} / \mathrm{Si}$ ratios were calibrated with $\mathrm{Ca}_{2} \mathrm{SiO}_{4}$. Matrix corrections were made using the PhiRhoZ method.

Each indentation zone was imaged in back-scattered electron (BSE) mode, as well as in secondary electron (SE) mode. The former facilitated visualization of the unreacted cement grains (which yield high atomic number contrast), while the latter facilitated visualization of the small indent impressions $(\approx 1 \mu \mathrm{m})$ left by the Berkovich indenter. To aid in isolating microvolumes solicited solely from hydrated phases, each imprint was assigned to 1 or 4 'phases': 1) surface defect (e.g., void, crack, pit), 2) residual clinker grain, 3) inner product (IP) hydrates or hydrates formed within several micrometers of cement grains grain, and 4) outer product (OP) hydrates.

\section{Results}

\subsection{Comparison of microvolumes in nanoindentation and SEM-EDS experiments}


To directly compare the results from nanoindentation and SEM-EDS, it was necessary to verify that the microvolumes probed by each method were of comparable size. Figure 2 shows a cross-section of an indented region, where the results of Monte Carlo (MC) and fine element (FE) simulations are superimposed. The Monte Carlo simulation, performed in $\mathrm{CASINO}^{32}$ and using as input parameters the SEM operating conditions noted in Section 2.3, showed electron trajectories reaching a normalized depth of $z / h_{\max } \approx 6-7$, or a real depth of $\approx 2.0 \mu \mathrm{m}\left(h_{\max }=310 \mathrm{~nm}\right)$. The maximum depth at which characteristic X-rays are generated in SEM-EDS will be slightly smaller than this value, due to the fact that the most deeply penetrating electrons will have insufficient energy to promote inner shell electron ionizations. ${ }^{33}$ The results of FE simulations, performed in $\mathrm{ABAQUS}^{34}$, are represented in Figure 2 as isocontours of the normalized local strain energy density field. The calculation assumed axisymmetrical conditions. The Berkovich tip was approximated by a cone of half-angle $70.3^{\circ}$. The strength properties of the indented material (assumed elastoplastic, with a yield strength-to-modulus ratio of $10^{-1.5}$ ) were chosen such that the computed contact depth-to-indentation depth ratio, $h_{c} / h_{\max }$, was close to that measured experimentally on cement pastes $\left(h_{c} / h_{\max } \approx 0.88\right)$. Results show that the microvolume probed by nanoindentation has a characteristic size of $z / h_{\max } \approx 5$, or approximately $1.5 \mu \mathrm{m}$. These results thus illustrate that the microvolume probed by nanoindentation was comparable to that probed by SEM-EDS.

\subsection{Nanoindentation coupled with BSE-imaging}

After performing a grid indentation analysis, the indented sample was analyzed in the SEM. Figure 3 shows a SEM-BSE image of a typical zone of the hydrated cement paste subjected to the grid indentation test; 16 indents are shown, each marked by an triangle, exaggerated in size for visibility. As described in Section 2.3, each indent was located and visually classified in the SEM as either (1) surface defect, (2) residual clinker grain, (3) inner product (IP) or near-grain hydrate, and (4) outer product (OP) hydrate. Surface defects, generated during the polishing process to prepare the flat specimens, were present as cracks and pop-outs of hydrated paste regions adjacent to clinker grains (see Figure 3). Of the 240 indents analyzed, 15\% represented surface defects, 32\% residual (unhydrated) clinker grains, $25 \%$ OP hydrates, and $18 \% \mathrm{IP} /$ near-grain hydrates. The degree of hydration for the hydrated paste, calculated as 
$\alpha=1-f_{\text {cem,residual }}\left(\rho_{c} \cdot w / c+1\right)=0.48$ (assuming $\rho_{c}=3.15, f_{\text {cem,resid }}=0.32$ ), is in good agreement with Powers's model of hydrated cement paste. ${ }^{9}$

Since each point in the nanoindentation grid was assigned a phase as defined above, it was possible to decompose the total frequency distribution curves for indentation modulus $(M)$ and indentation hardness $(H)$ into their respective phases (Figure 4). Both the $M$ and $H$ distribution curves show three major peak families. 1) The peak at low $M$ and $H$, centered around 40-45 GPa and 1.2-1.3 GPa, respectively, and spanning 30-55 GPa and 0.7-2.0 GPa, respectively, represent hydrated phases-comprising both the IP and OP variety. Note that these values exceed the reported nanoindentation values of LD and HD C-S$\mathrm{H}^{16-18}$, yet they are close to the characteristic elasticity values of portlandite, $M=38.0 \pm 5 \mathrm{GPa}$, as obtained from nanoindentation on large $\mathrm{CH}$ crystals ${ }^{35}$ and from molecular dynamic simulation on $\mathrm{CH}(M=39$ $\mathrm{GPa}) .{ }^{35}$ From purely mechanical evidence, the hydrates formed in this $w / c=0.20$ cement paste appear to resemble a chemical phase intermediate between portlandite and $\mathrm{HD} \mathrm{C}-\mathrm{S}-\mathrm{H}$. There is little to no evidence for LD C-S-H or for 'spurious' peaks ${ }^{65}$ produced artificially by averaging the mean values of a mix of hydrated phases characterized by an indentation modulus of $M \leq 65 \mathrm{GPa}$ and a hardness of $H \leq 3 \mathrm{GPa}^{45,66}$ 2) The peak at high $M$ and $H$, centered around $120 \mathrm{GPa}$ and 7-9 GPa, respectively, are clearly associated with the residual clinker grains, as demonstrated in earlier studies. ${ }^{16}$ 3) The intermediate shoulder centered on $M=80-90 \mathrm{GPa}$ and $H=3.0-3.5 \mathrm{GPa}$ displays properties well above the particle properties of hydrated phases (i.e., $M \leq 65 \mathrm{GPa}$ and a hardness of $H \leq 3 \mathrm{GPa}^{45}$ ). Thus, this peak is not representative of a hydrated phase, but is clearly identified as mixtures of clinker and hydrated phases in the probed microvolume. This peak —a result of the unusually high concentration of residual clinker—can legitimately be considered a 'spurious' peak. Thus, a combination of nanoindentation and knowledge of the intrinsic hydrate solid properties allow us to assign this mechanical "phase" as a hydrate-clinker composite phase. ${ }^{66}$ This phase is disregarded in subsequent analyses.

\subsection{Nanoindentation coupled with SEM-EDS}

The objective of coupling the nanoindentation data with the SEM-EDS results was to shed light on the chemical nature of the UHD mechanical phase. As discussed in Section 3.2, the UHD phase showed 
unexpectedly high $M$ and $H$ values, suggesting mechanical properties intermediate between those of HD $\mathrm{C}-\mathrm{S}-\mathrm{H}$ and portlandite. It was thus decided to isolate only those indents whose microvolumes comprised solely $\mathrm{C}-\mathrm{S}-\mathrm{H}$ and $\mathrm{CH}$. This was done in a series of steps. 1) First, all points associated with surface defects (e.g., pop-outs near grain boundaries) and clinker grains were removed from the analysis. 2) All microvolumes whose SEM-EDS oxide totals exceeded 0.76 (i.e., the theoretical value for portlandite) were then removed, since they represent admixtures of clinker and hydrated phases. Similarly, all microvolumes whose SEM-EDS oxide totals were less than 0.68 (i.e., corresponding to $\mathrm{C}-\mathrm{S}-\mathrm{H}$ compositions with water contents exceeding that represented in the formula, $1.8 \mathrm{CaO} \cdot \mathrm{SiO}_{2} \cdot 4.2 \mathrm{H}_{2} \mathrm{O}^{\S}$ ) were removed, since they represent admixtures of $\mathrm{C}-\mathrm{S}-\mathrm{H}$ and either high water-content hydrates such as ettringite (oxide content $\approx 0.54$ ), capillary pores, or both. The points remaining in the analysis, representing microvolumes comprised largely (but not exclusively) of $\mathrm{C}-\mathrm{S}-\mathrm{H}$ and $\mathrm{CH}$, were thus bound between $0.68<$ oxide total $<0.76$; this can be visualized on the $\mathrm{Si} / \mathrm{Ca}$ versus oxide total plot as the filled points between the two dashed vertical lines (Figure 5). 3) These selected points were further analyzed to eliminate any points with small amounts of admixed ferrite clinker phase or of hydrated calcium sulfoaluminate phases (e.g., ettringite (ETT), monosulfoaluminate (MON)). This was accomplished by plotting $\mathrm{Si} / \mathrm{Ca}$ versus $(\mathrm{Fe}+\mathrm{Al}$ )/Ca (Figure $6 \mathrm{a})$ and $\mathrm{Si} / \mathrm{Ca}$ versus $\mathrm{S} / \mathrm{Ca}$ (Figure $6 \mathrm{~b}$ ) and taking only those points scattered closely around the $\mathrm{CH} / \mathrm{C}-\mathrm{S}-\mathrm{H}$ tie-lines in both graphs (shown as filled points within the dashed curves). The lack of points clearly on the MON/C-S-H or ETT/C-S-H tie-lines most likely indicates that, when present, monosulfoaluminate and ettringite are closely admixed with both $\mathrm{C}-\mathrm{S}-\mathrm{H}$ and $\mathrm{CH}$.

The remaining points after the above treatment yield microvolumes with differing amounts of $\mathrm{CH}$ and $\mathrm{C}-\mathrm{S}-\mathrm{H}$. The volume fraction of $\mathrm{CH}$ in each microvolume, $f_{\mathrm{CH}}$, was measured as $f_{C H}=x_{C H} \rho_{\text {paste, } i} / \rho_{C H}$, where $x_{C H}$ is the mass fraction of $\mathrm{CH}$ in the microvolume (measured by EDS), $\rho_{C H}$ is the density of portlandite (i.e., $2.24 \mathrm{~g} / \mathrm{cm}^{3}$ ), and $\rho_{\text {paste, } i}$ is the density of the hydrated paste. The latter was calculated in

\footnotetext{
$\S$ This composition is consistent with the generally accepted composition of water-saturated C-S-H (i.e., C-S-H with minimum oxide content), $1.8 \mathrm{CaO} \cdot \mathrm{SiO}_{2} \cdot 4.0 \mathrm{H}_{2} \mathrm{O}{ }^{1}$
} 
two ways (see Appendix A). In case 1, a microcomposite of $\mathrm{C}-\mathrm{S}-\mathrm{H}$ and $\mathrm{CH}$ was assumed, where the latter was assumed to precipitate outside the gel pores of $\mathrm{C}-\mathrm{S}-\mathrm{H}$. In case 2, a nanocomposite of $\mathrm{C}-\mathrm{S}-\mathrm{H}$ and $\mathrm{CH}$ was assumed where $\mathrm{CH}$ precipitates within the gel pores of $\mathrm{C}-\mathrm{S}-\mathrm{H}$. The average value and standard deviation of $f_{C H}$ was computed from the two values for $\rho_{\text {paste }, i}$ calculated at each indentation point. This calculation permitted a plot of $f_{C H}$ versus indentation modulus, $M$, and $f_{\mathrm{CH}}$ versus indentation hardness, $H$, as shown in Figure $7 \mathrm{a}$ and $7 \mathrm{~b}$, respectively. Also present are the respective $(M, H)$ values for $\mathrm{HD} \mathrm{C}-\mathrm{S}-\mathrm{H}$ $\left(f_{C H}=0\right)$ and portlandite $\left(f_{C H}=1\right) ; M$ values were taken from atomistic simulations, ${ }^{36,37} \mathrm{H}$ values from nanoindentation. ${ }^{16}$ Figure 7 shows two important observations. First, the range of observed values for $M$ and $H$ (spanning 30-55 GPa and 0.8-2.0 GPa, respectively) correspond to the values associated with the UHD phase. Second, as is somewhat more apparent in the indentation modulus data (Figure 7a), increasing the amount of $\mathrm{CH}$ from pure $\mathrm{HD} \mathrm{C}-\mathrm{S}-\mathrm{H}$ (i.e., $f_{C H}=0$ ) sharply increases $M$, up to $f_{C H} \approx 0.15-$ 0.20; at this point, subsequent increases in $\mathrm{CH}$ show no significant change in $M$, with values scattered around $M \approx 45 \mathrm{GPa}$. This value is close to that of pure portlandite. ${ }^{37}$

\section{Discussion}

\subsection{Micromechanical analysis: evidence for $\mathrm{C}-\mathrm{S}-\mathrm{H} / \mathrm{CH}$ nanocomposites}

To understand the influence of microstructure on the mechanical response observed in Figure 7, we computed via micromechanics the elastic response of two plausible structures for the $\mathrm{C}-\mathrm{S}-\mathrm{H} / \mathrm{CH}$ mixture. In both cases, we assume, for the $w / c=0.20$ cement paste, the presence of $\mathrm{HD} \mathrm{C}-\mathrm{S}-\mathrm{H}$ (with intrinsic porosity $\left.\phi_{0}=0.25^{14,17}\right), \mathrm{CH}$, and no capillary pores (consistent with the Powers model ${ }^{9}$ ). See Appendix B for further details on micromechanics theory.

Case 1: Microcomposite. $\mathrm{CH}$ precipitates outside the gel pores of $\mathrm{C}-\mathrm{S}-\mathrm{H}$. Regardless of the spatial arrangement, the homogenized stiffness of the $\mathrm{C}-\mathrm{S}-\mathrm{H} / \mathrm{CH}$ bi-composite must fall between the following energy bounds of Voigt and Reuss: $:^{38,39}$

$$
0 \leq f_{C H} \leq 1:\left\{\begin{array}{l}
\mathbf{C}_{\mathrm{hom}}^{L B}=\left\langle\mathbf{c}_{r}^{-1}\right\rangle_{V}^{-1} \\
\mathbf{C}_{\mathrm{hom}}^{U B}=\left\langle\mathbf{c}_{r}\right\rangle_{V}
\end{array} \text { with } \quad r=\{1: \mathrm{CH}, 2: \mathrm{HD} \mathrm{C}-\mathrm{S}-\mathrm{H}\}\right.
$$


where $\mathbf{c}_{r}$ is the isotropic elastic stiffness of the $r_{-}{ }^{\text {th }}$ phase, $\mathbf{C}_{\text {hom }}^{L B}$ and $\mathbf{C}_{\text {hom }}^{U B}$ are the lower bound and upper bound homogenized stiffness tensors, and the graph brackets represent volume averages.

Case 2: Nanocomposite. $\mathrm{CH}$ precipitates within the gel pores of $\mathrm{C}-\mathrm{S}-\mathrm{H}$. At low $f_{C H}$, $\mathrm{CH}$ nanocrystals fill the $\mathrm{C}-\mathrm{S}-\mathrm{H}$ gel porosity, $\phi_{0}$, thus forming an intimate $\mathrm{C}-\mathrm{S}-\mathrm{H} / \mathrm{CH}$ nanocomposite (see Figure $8 \mathrm{~b}$, 'Level I'). This filling, assumed to occur to varying extents, increases up to a critical $\mathrm{CH}$ volume fraction, $f_{\text {CHcrit }}$ (which ranges from 0 to $\phi_{0}$ ). In the general case, where there is partial filling of the gel porosity, there will be a residual porosity, $\phi_{c r i t}$ defined as $\phi_{c r i t}=\phi_{0}-f_{C H, \text { crit. }}$. For $f_{C H}<f_{C H c r i t}$, the homogenized stiffness is estimated by mean average theory as follows:

$0 \leq f_{C H} \leq f_{C H c r i t}: \quad \mathbf{C}_{\text {hom }}^{I}=\left\langle\mathbf{c}_{r}: \mathbf{A}_{r}^{S C}\right\rangle_{V} \quad \mathrm{r}=\{1:$ nano CH; 2: globule; 3: pore $\}$

where $\mathbf{A}_{r}^{S C}$ is the Self-Consistent localization tensor of spherical inclusions. ${ }^{40,41}$

The $\mathrm{CH}$ occurring above $f_{\text {CHcrit }}$ is assumed to be present as microscale $\mathrm{CH}$ crystals located outside the gel pores. Thus, for $f_{C H}>f_{C H c r i t}$ we assume a mixture of the $\mathrm{C}-\mathrm{S}-\mathrm{H} / \mathrm{CH}$ nanocomposite and of microscale $\mathrm{CH}$ crystals. The homogenized stiffness of such a double-scale microstructure, represented in the 'Level II' structure in Figure $8 b$, is expressed as

$f_{C H}>f_{\text {CHcrit }}: \quad \mathbf{C}_{\text {hom }}^{I I}=\left\langle\mathbf{c}_{r}: \mathbf{A}_{r}^{M T}\right\rangle_{V} \quad \mathrm{r}=\left\{1:\right.$ matrix with $\mathbf{C}_{\text {hom }}^{I}$ at $\phi=\phi_{\text {crit }} ; 2:$ micro CH $\}$

where $\mathbf{A}_{r}^{M T}$ is the Mori-Tanaka localization tensor of spherical inclusions. ${ }^{42}$ The volume fractions of the phases vary linearly with $f_{C H}$ :

$0 \leq f_{C H} \leq f_{\text {CHcrit }}:\left\{\begin{array}{l}f_{\text {pore }}=\phi_{0}+\left(\phi_{\text {crit }}-\phi_{0}\right) \frac{f_{C H}}{f_{C H \text { crit }}} \\ f_{\text {Globule }}=1-f_{\text {pore }}-f_{\text {nano } C H}=1-\phi_{0} \\ f_{\text {nanoCH }}=f_{C H}\end{array}\right.$ 
$f_{C H}>f_{\text {CHCrit }}:\left\{\begin{array}{l}f_{\text {microCH }}=\left(f_{C H}-f_{\text {CHcrit }}\right) /\left(1-f_{\text {CHcrit }}\right) \\ f_{\text {matrix }}=1-f_{\text {microCH }}\end{array}\right.$

where $f_{\text {matrix }}$ is the volume fraction of matrix ('Level 1') with homogenized stiffness expressed in eq. (5) at $\phi=\phi_{c r i t}$. As in previous work, ${ }^{16,43}$ the Self-Consistent scheme and the Mori-Tanaka scheme are adopted for the granular-like structure of $\mathrm{C}-\mathrm{S}-\mathrm{H}$ and for the matrix-inclusion microstructure of the cement paste, respectively. Note that the assumption of spherical localization tensor is justified by the fact that the shape effect of randomly oriented C-S-H inclusions is a secondary effect for porosity less than $30 \% .{ }^{43,44}$

Table 1 reports the input parameters for the micromechanics model, as well as data from the literature. The elastic properties of C-S-H solid phase, here called "globule", were identified by inverse analysis of nanoindentation results ${ }^{35}$ and recently confirmed by atomistic modelling ${ }^{35,36,45}$ and by quantum-mechanics density functional theory. ${ }^{46}$ The porosity of HD C-S-H is taken as $\phi_{0}=0.25$ in accordance with previous works, which cite values between $0.24-0.26 .^{14,18,47}$ The elastic constants of portlandite, calculated by use of density functional theory, ${ }^{37}$ were taken as $\mathrm{C}_{11}=99.39 \mathrm{GPa}, \mathrm{C}_{12}=30.78 \mathrm{GPa}, \mathrm{C}_{33}=36.29, \mathrm{C}_{44}=7.88$, $\mathrm{C}_{66}=34.31 \mathrm{GPa}$. For the sake of simplicity, the Voigt-Reuss-Hill (VRH) estimates of isotropic elastic properties for the portlandite are calculated by using the full elastic tensor of the single crystal and the arithmetic mean of the Voigt and Reuss averaging schemes. ${ }^{48}$

Figure 8a compares the experimental results with the micromechanics predictions for the 2 microstructural cases. The energy bounds of 'case l', representing a pure microcomposite of CH and CS-H (dashed lines), underestimate most of the experimental data. These bounds are narrow due to the low stiffness contrast between $\mathrm{CH}$ and $\mathrm{HD} \mathrm{C}-\mathrm{S}-\mathrm{H}$. The curves for 'case 2', which assume a $\mathrm{CH} / \mathrm{C}-\mathrm{S}-\mathrm{H}$ nanocomposite with different values of $\phi_{c r i t}$, capture the data notably better, especially at low $f_{C H}$, where there is a steep rise in $M$. Note that the assumed value of the elastic modulus of $\mathrm{CH}$ has little influence on this conclusion, as it only influences the curves at high $f_{C H}$. The calculations also show that the majority of the data are consistent with $\phi_{\text {crit }}$ values between $0.10-0.20$, suggesting that $\mathrm{CH}$ fills $40-80 \%$ of the initial HD C-S-H porosity. The fact that nearly all the data lie within the envelope created by the curves for the 
pure microcomposite and those for the nanocomposite suggest that the dispersion in the data result from the coexistence of the two microstructural arrangements in the system.

\subsection{Implications of nanoscale $\mathrm{CH}$ to the structure and properties of cement paste}

A central finding of the study is that the UHD phase identified in earlier nanoindentation studies ${ }^{17,18}$ is, in fact, a nanocomposite of $\mathrm{HD} \mathrm{C}-\mathrm{S}-\mathrm{H}$ and nanoscale $\mathrm{CH}$. Micromechanical analyses presented in Section

4.1 show that the latter occupy a variable fraction of the total $\mathrm{HD} \mathrm{C}-\mathrm{S}-\mathrm{H}$ gel porosity.

While $\mathrm{CH}$ is conventionally thought to precipitate in the capillary space as relatively large crystals of tens of micrometers or larger, the $\mathrm{CH}$ nanocrystals proposed to reside in the pores of $\mathrm{C}-\mathrm{S}-\mathrm{H}$ are over an order of magnitude smaller, approximately several nanometers across. The existence of nanoscale $\mathrm{CH}$ is supported in the literature. ${ }^{26,49,50,65}$ For example, Groves, ${ }^{49}$ using TEM on low $w / c$ ratio cement paste (prepared at $w / c=0.25$, then compressed to an effective $w / c=0.15$ ), showed the presence of $\mathrm{CH}$ with lamella thicknesses of $\approx 10 \mathrm{~nm}$. These crystals were intimately embedded in the $\mathrm{C}-\mathrm{S}-\mathrm{H}$ gel, which led the author to speculate that the $\mathrm{CH}$ inclusions were mechanically reinforcing the gel. This supposition has been directly confirmed in the current study. Small amounts of nanoscale $\mathrm{CH}$ have also been observed at higher $w / c$ ratios (e.g., $w / c=0.40)$ by $\mathrm{TEM}^{50}$ and $\mathrm{SANS}^{26}$. The intermixing of nanoscale $\mathrm{CH}$ with $\mathrm{C}-\mathrm{S}-\mathrm{H}$ is also consistent with models of $\mathrm{C}-\mathrm{S}-\mathrm{H}$ at the crystal chemical level, where a defective-tobermorite $\mathrm{C}-\mathrm{S}-$ $\mathrm{H}$ structure admixed with nanoscale $\mathrm{CH}$ has been found to best describe certain systems. ${ }^{50,51}$

The introduction of nanoscale $\mathrm{CH}$ in the gel pores of $\mathrm{C}-\mathrm{S}-\mathrm{H}$ will have a strong influence on the volumetric changes in cement paste. For example, the replacement of evaporable water for solid $\mathrm{CH}$ in the C-S-H gel pores will increase the stiffness of the solid, as well as decrease the volume of gel pores that can generate high capillary pressures during drying (arising from the high curvature of the liquid-vapor menisci). Both of these effects should reduce the driving force for drying shrinkage and potential cracking. ${ }^{52}$ The increased solid density of the $\mathrm{C}-\mathrm{S}-\mathrm{H} / \mathrm{CH}$ nanocomposite would furthermore expect to decrease creep due to the greater resistance against the sliding of C-S-H particles. ${ }^{18}$ 
If we assume a surface energy, $\gamma_{C L}$, and curvature, $\kappa_{C L}$, of the nanoscale $\mathrm{CH}$ crystal, the equilibrium solubility, $C$, of the nanoscale crystal increases with respect to that of a micrometer-sized (flat) crystal according to ${ }^{3}$

$$
\kappa_{C L} \gamma_{C L}=\frac{R_{g} T}{V_{c}} \ln \left(C / C_{0}\right)
$$

where $R_{g}$ is the ideal gas constant, $V_{c}$ the molar volume of $\mathrm{CH}$, and $C_{0}$ the solubility of a flat crystal. This phenomenon has several important implications. First, we conclude that nanoscale $\mathrm{CH}$ must form under conditions of high supersaturation. Since high supersaturations most likely occur near the interface between the dissolving cement grain and liquid pore solution, we can expect that the loci of nanoscale $\mathrm{CH}$ crystals will be found precisely here; this argument is further extended in Section 4.3. Second, if we encounter the possible scenario where the solution composition is undersaturated with respect to the nanoscale $\mathrm{CH}$ crystal, but supersaturated with respect to the micrometer-scale $\mathrm{CH}$ crystal residing in the capillary space (which could occur just after precipitation of nanoscale $\mathrm{CH}$ from a transient supersaturated solution), we would expect the growth of the micrometer-scale $\mathrm{CH}$ crystals at the expense of the nanoscale $\mathrm{CH}$ crystals (i.e., Oswald ripening). This process would logically degrade the mechanical properties of the nanocomposite, provided there is sufficient capillary space for the growth of micrometer-sized $\mathrm{CH}$ crystals. This condition would be possible in (porous) high $w / c$ ratio paste, but unlikely in (dense) low $w / c$ ratio paste, where the Oswald ripening mechanism would thus be strongly impeded. Lastly, we could encounter the scenario where a sustained supersaturation exists. This situation could arise near a dissolving cement grain that lacks local space for precipitating new $\mathrm{CH}$ crystals. To maintain equilibrium of the existing nanoscale $\mathrm{CH}$ crystals (i.e., to prevent them from growing), the surrounding matrix needs to apply a counterbalancing pressure on the crystals. This pressure, $p_{c}$, which arises from the push of the crystal on the pore wall, is directly related to the supersaturation in the liquid:

$$
p_{c}-p_{l}=\frac{R_{g} T}{V_{c}} \ln \left(C / C_{0}\right),
$$


where $p_{l}$ is the pressure in the liquid. This crystallization pressure induced by nanoscale $\mathrm{CH}$ provides a viable mechanism for the poorly understood expansion observed in low $w / c$ ratio cement pastes. ${ }^{53,54}$

\subsection{Mechanism of forming $\mathrm{C}-\mathrm{S}-\mathrm{H} / \mathrm{CH}$ nanocomposites during cement hydration}

The scatter in the $f_{C H}$ versus $M$ data in Figure 7 between the extreme bounds of the micromechanical analysis suggests that, in addition to being able to form a $\mathrm{C}-\mathrm{S}-\mathrm{H} / \mathrm{CH}$ nanocomposite, $\mathrm{C}-\mathrm{S}-\mathrm{H}$ and $\mathrm{CH}$ can also form a pure microcomposite, whereby micrometer-scale $\mathrm{CH}$ crystals precipitate outside the gel pore volume of $\mathrm{C}-\mathrm{S}-\mathrm{H}$. The coexistence of both structures in a cement paste leads to the fundamental question: under what conditions do $\mathrm{C}-\mathrm{S}-\mathrm{H} / \mathrm{CH}$ nanocomposites form? From nanoindentation experiments at different $w / c$ ratios, ${ }^{18}$ it is clear that the formation of the nanocomposite is encouraged at low $w / c$ ratios, especially for $w / c$ ratios below 0.3 , and very markedly below 0.2 . This $w / c$ range coincides with the range in which (unhydrated) cement particles in a fresh cement paste initially begin to impinge due to a deficiency in water to fill the pores of a dry cement pack (which has a representative packing fraction of 0.55-0.60). From this evidence, we hypothesize that the $\mathrm{C}-\mathrm{S}-\mathrm{H} / \mathrm{CH}$ nanocomposite is a direct consequence of a local deficiency of water and space. Such a lack of water would occur in regions where cement particles are in close proximity, separated by films or wedges of water as small as tens of nanometers thick (Figure 9). In these highly confined reaction zones, where supersaturation in the liquid is presumably high (as argued above), there will likely be a tendency to favor reaction paths that minimize atomic transport; calculations of atomic fluxes presented below support this hypothesis. In regions where there is a local excess of water for hydration, such as in the interstices between cement particles (Figure 9), there is a greater facility for $\mathrm{CH}$ to precipitate as micrometer crystals, thereby forming a microcomposite with $\mathrm{C}-\mathrm{S}-\mathrm{H}$. By these above mechanisms, we can thus account for both the nanocomposite and microcomposite structures observed in the $w / c=0.20$ paste. The above mechanism also suggests, that if the interstices between cement grains are filled with ultrafine fillers, such as in ultrahigh performance concretes, ${ }^{55}$ we may expect a greater potential for forming a nanocomposite structure due to the reduction in available capillary space. 
Table 2 shows the number of $\mathrm{Ca}, \mathrm{Si}, \mathrm{O}$, and $\mathrm{H}$ atoms in a $1 \mathrm{~cm}^{3}$ volume of $\mathrm{C}_{3} \mathrm{~S}, \mathrm{HD} \mathrm{C}-\mathrm{S}-\mathrm{H}$, and the $\mathrm{C}-$ $\mathrm{S}-\mathrm{H} / \mathrm{CH}$ nanocomposite. The atomic densities in the reactant and product phases yield insight into to the flux of atoms across interfaces. For example, the observation that the O-densities of $\mathrm{C}_{3} \mathrm{~S}, \mathrm{HD} \mathrm{C}-\mathrm{S}-\mathrm{H}$ and $\mathrm{C}-\mathrm{S}-\mathrm{H} / \mathrm{CH}$ nanocomposite are nearly equal suggests that there is little, if any, long-range movement of the oxygen anions during hydration. ${ }^{56}$ This process would suggest an efficient mechanistic pathway, whereby, upon contact of the hydrated surface with water, $\mathrm{H}$ diffuses through the inner product (instead of the bulkier water molecule), while $\mathrm{Ca}$ and $\mathrm{Si}$ atoms diffuse out to the capillary space (to form OP hydrates). Compared to an equal volume of $\mathrm{HD} \mathrm{C}-\mathrm{S}-\mathrm{H}$, the $\mathrm{C}-\mathrm{S}-\mathrm{H} / \mathrm{CH}$ nanocomposite (with an assumed $f_{C H}=0.15$ ) reduces the required efflux of $\mathrm{Ca}$ atoms to the capillary space by $25 \%$, as well as the required influx of $\mathrm{H}$ by $12 \%$. As argued above, both of these trends would be favored in the highly confined reaction conditions in low $w / c$ ratio cement paste.

\section{Conclusions}

This study provides the first direct evidence for the mechanical reinforcing effect of nanoscale $\mathrm{CH}$ crystals embedded in a $\mathrm{C}-\mathrm{S}-\mathrm{H} / \mathrm{CH}$ nanocomposite structure. This nanocomposite structure is particularly prone to form during the hydration of low $w / c$ ratio cement paste. In these concentrated systems, it is believed that the numerous near-contact points separating cement grains creates confined reaction zones that are characterized by high supersaturations in the aqueous phase and by a lack of available space - two factors that should encourage nanocomposite formation. In contrast, in the interstices between grains where there is ample space for microscale $\mathrm{CH}$ to crystallize, microcomposites of $\mathrm{CH}$ and $\mathrm{C}-\mathrm{S}-\mathrm{H}$ are believed to preferentially form, which experiment and micromechanical modeling show to have lower elastic moduli compared to those of the nanocomposites. This reasoning furthermore suggests that ultrafine fillers, which fill the interstices between cement grains, should encourage nanocomposite formation. On a general level, this study illustrates the great potential in coupling X-ray microanalysis, nanoindentation, and micromechanics to advance our understanding of the relationships between chemistry, nanostructure, and mechanics in highly heterogeneous materials. 


\section{Acknowledgements}

We gratefully acknowledge D. Lapillonne, S. Lombard, and S. Brun at Lafarge Centre de Recherche for carrying out the experimental work on the SEM.

\section{Appendix A. Calculation of cement paste density from SEM-EDS data}

As described in Section 3.3, 2 density values were calculated at each SEM-EDS spot analysis.

For 'case 1', a microcomposite of C-S-H (including empty gel pores) and $\mathrm{CH}$ was assumed, the density thus calculated as,

$\rho_{\text {paste, } \text { micro }}=\left[x_{C H}\left(1-x_{C H}\right)^{-1}+1\right] /\left[x_{C H}\left(1-x_{C H}\right)^{-1} \rho_{C H}^{-1}+\rho_{C S H, d r y}^{-1}\right]$

where $\rho_{C S H, d r y}$ is the bulk dry density of HD C-S-H, computed as, $\rho_{C S H, d r y}=\rho_{g l o b u l e} /\left(1+\phi_{0}\left(1-\phi_{0}\right)^{-1}\right)$. Thus, assuming $\rho_{\text {globule }}=2.6 \mathrm{~g} \mathrm{~cm}^{-3}$ and $\phi_{0}=0.25, \rho_{C S H, d r y}=1.95 \mathrm{~g} \mathrm{~cm}^{-3}$.

For 'case 2', a nanocomposite of $\mathrm{C}-\mathrm{S}-\mathrm{H}$ and $\mathrm{CH}$ was assumed where the $\mathrm{CH}$ was assumed to precipitate in the gel pores of C-S-H. This substitution increases with $x_{C H}$, until $x_{C H}=0.22$, when the pores of HD C-S-H (with $\phi_{0}=0.25$ ) are theoretically full; subsequent increases in $x_{C H}$ thus translate into a composite of the $\mathrm{C}-\mathrm{S}-\mathrm{H} / \mathrm{CH}$ nanocomposite (with complete replacement of $\mathrm{CH}$ for gel pores) and of microscale $\mathrm{CH}$. The density for this case thus reads as follows:

$\rho_{\text {paste, }, \text { ano }}=\rho_{C S H, d r y}\left(1-x_{C H}\right)^{-1}$ for $x_{C H} \leq 0.22$

$\left.\rho_{\text {paste, nano }}=\left[\left(1-x_{C H^{\prime}}\right) x_{C H^{\prime}}{ }^{-1}+1\right] /\left[1-x_{C H^{\prime}}\right) \rho_{C S H / C H}{ }^{-1}+\rho_{C H}\right]$ for $x_{C H}>0.22$

where $\rho_{\mathrm{CSH} / \mathrm{CH}}$ is the density of the 'CH-saturated' $\mathrm{C}-\mathrm{S}-\mathrm{H} / \mathrm{CH}$ nanocomposite, equal to $2.51 \mathrm{~g} \mathrm{~cm}^{-3}$.

\section{Appendix B. Basics of continuum micromechanics}

In linear elastic continuum micromechanics, the macroscopic $2^{\text {nd }}$ order tensor $\mathrm{s}$ for strain and stress, $\mathrm{E}$ and $\Sigma$, applied to the representative elementary volume $\mathrm{V}$ are simply defined as the averages of the microscopic counterparts $\varepsilon(x)$ and $\sigma(x)$ :

$\mathrm{E}=\langle\varepsilon(x)\rangle_{\mathrm{V}} ; \quad \Sigma=\langle\sigma(x)\rangle_{\mathrm{V}}=\left\langle\mathbf{c}_{\mathrm{r}}: \varepsilon(x)\right\rangle_{\mathrm{V}}$ 
where $\mathbf{c}_{\mathrm{r}}$ is the $4^{\text {th }}$ order stiffness tensor of the single phase, $x$ is the vector position, and $\langle y\rangle_{V}=1 / V \int y d V$ denotes the volume average of quantity $y$ over the domain $V$. The concept of localization $4^{\text {th }}$ order tensor $\mathbf{A}_{r}(x)$ is employed to relate the microscopic strain $\varepsilon(x)$ at point $x$, within the $\mathrm{r}^{\text {th }}$ phase, with the macroscopic strain $\mathrm{E}$ as follows

$$
\varepsilon(x)=\mathbf{A}_{\mathrm{r}}(x): \mathrm{E}
$$

The localization tensor $\mathbf{A}_{r}$ is a key concept as it lumps all the information about the microstructure morphology. Substituting eq. (B.1) and eq. (B.3) into the stress average of eq. (B.2) yields the homogenized stiffness of the composite:

$$
\mathbf{C}_{\text {hom }}=\left\langle\mathbf{c}_{r}: \mathbf{A}_{r}\right\rangle_{V}
$$

For a matrix-inclusion morphology, the Mori-Tanaka localization tensor is frequently employed

$$
\mathbf{A}_{\mathrm{r}}^{\mathrm{MT}}=\left[\mathrm{I}+\mathbf{S}_{m}:\left(\mathbf{c}_{\mathrm{m}}^{-1}: \mathbf{c}_{\mathrm{r}}-\mathbf{I}\right)\right]^{-1}:\left\langle\left[\mathbf{I}+\mathbf{S}_{\mathrm{m}}:\left(\mathbf{c}_{\mathrm{m}}^{-1}: \mathbf{c}_{r}-\mathbf{I}\right)\right]^{-1}\right\rangle_{V}^{-1}
$$

where $\mathbf{S}_{\mathbf{m}}$ is the 4th order Eshelby tensor of the inclusion within the matrix, which depends on the elastic properties of the matrix ${ }^{41,57}$. In contrast, for a granular morphology, the General Self-Consistent localizer tensor $^{40}$ is employed

$$
\mathbf{A}_{\mathrm{r}}^{\mathrm{SC}}=\left[\mathrm{I}+\mathbf{S}_{\mathrm{hom}}:\left(\mathbf{C}_{\mathrm{hom}}^{-1}: \mathbf{c}_{\mathrm{r}}-\mathbf{I}\right)\right]^{-1}:\left\langle\left[\mathbf{I}+\mathbf{S}_{\mathrm{hom}}:\left(\mathbf{C}_{\mathrm{hom}}^{-1}: \mathbf{c}_{r}-\mathbf{I}\right)\right]^{-1}\right\rangle_{V}^{-1}
$$

where $\mathbf{S}_{\text {hom }}$ is the Eshelby tensor of the inclusion within a matrix of which elastic properties coincide with the homogenized material. In the case of randomly oriented C-S-H fibers, the Eshelby tensor $\mathbf{S}$ obtained from a geometric procedure of orientation averaging is still isotropic. ${ }^{41}$ 


\section{References}

${ }^{1}$ H. F. W. Taylor, Cement Chemistry, 2nd ed. Thomas Telford, London (1997).

${ }^{2}$ H. M. Jennings, J. J. Thomas, J. S. Gevrenov, G. Constantinides, and F.-J. Ulm, "A Multi-Technique Investigation of the Nanoporosity of Cement Paste," Cem. Concr. Res., 37[3] 329-36 (2007).

${ }^{3}$ Z. P. Bazant, A. B. Hauggaard, S. Baweja, and F.-J. Ulm, "Microprestress-Solidification Theory for Concrete Creep. 1. Aging and Drying Effects," J. Eng. Mech.-ASCE, 123[11] 1188-94 (1997).

${ }^{4}$ P. Acker, "Swelling, Shrinkage and Creep: A Mechanical Approach to Cement Hydration," Mater. Struct., 37[268] 237-43 (2004).

${ }^{5}$ F.-J. Ulm, G. Constantinides, and F. H. Heukamp, "Is Concrete a Poromechanics Material?—A Multiscale Investigation of Poroelastic Properties," Mater. Struct., 37[265] 43-58 (2004).

${ }^{6}$ G. W. Scherer, "Crystallization in Pores," Cem. Concr. Res., 29, 1347-58 (1999).

${ }^{7}$ O. Coussy, "Poromechanics of Freezing Materials," J. Mech. Phys. Solids, 53[8] 1689-718 (2005).

${ }^{8}$ O. Coussy, "Deformation and Stress from In-Pore Drying-Induced Crystallization of Salt," J. Mech. Phys. Solids, 54[8] 1517-47 (2006).

${ }^{9}$ T. C. Powers and T. L. Brownyard, "Studies of the Physical Properties of Hardened Portland Cement Paste," J. Am. Concr. Inst., 43, 101-32, 249-336, 469-504, 49-602, 69-712, 845-57, 65-80, 933-69, 71-92.

${ }^{10}$ T. C. Powers, "Physical Properties of Cement Paste," pp. 577-609 in Proc. 4th Int. Symp. Chem. Cem., Vol. II, 1960.

${ }^{11}$ S. Brunauer, "Tobermorite Gel—-the Heart of Concrete," Am. Sci., 50[1] 210-29 (1962).

${ }^{12}$ R. F. Feldman and P. J. Sereda, "A New Model of Hydrated Cement and its Practical Implications," Eng. J. Can., 53, 53-59 (1970).

${ }^{13}$ H. M. Jennings, "A Model for the Microstructure of Calcium Silicate Hydrate in Cement Paste," Cem. Concr. Res., 30[1] 101-16 (2000).

${ }^{14} \mathrm{H}$. M. Jennings, "Refinements to Colloid Model of C-S-H in Cement: CM-II," Cem. Concr. Res., 38[3] 275-89 (2008).

${ }^{15}$ A. Donev, I. Cisse, D. Sachs, E. A. Variano, R. Stillinger, R. Connely, S. Torquato, and P. M. Chaikin, "Improving the Density of Jammed Disordered Packings using Ellipsoids," Sci. Technol. Adv. Mater., 303, 990-93 (2004). 
${ }^{16}$ G. Constantinides and F.-J. Ulm, "The Nanogranular Nature of C-S-H," J. Mech. Phys. Solids, 55[1] 64-90 (2007).

${ }^{17}$ F.-J. Ulm, M. Vandamme, C. Bobko, and J. A. Ortega, "Statistical Indentation Techniques for Hydrated Nanocomposites: Concrete, Bone, and Shale," J. Am. Ceram. Soc., 90[9] 2677-92 (2007).

${ }^{18}$ M. Vandamme and F.-J. Ulm, "Nanogranular Origin of Concrete Creep," Proc. Natl. Acad. Sci. U. S. A., 106[26] 10552-57 (2009).

${ }^{19}$ P. D. Tennis and H. M. Jennings, "A Model for Two Types of C-S-H in the Microstructure of Portland Cement Pastes," Cem. Concr. Res., 30[6] 855-63 (2000).

${ }^{20}$ G. Constantinides, K. S. R. Chandran, F.-J. Ulm, and K. J. Van Vliet, "Grid Indentation Analysis of Composite Microstructure and Mechanics: Principles and Validation," Mat. Sci. Eng. A-Struct., 430[1-2] 189-202 (2006).

${ }^{21}$ N. X. Randall, M. Vandamme, and F.-J. Ulm, "Nanoindentation Analysis as a Two-Dimensional Tool for Mapping the Mechanical Properties of Complex Surfaces," J. Mater. Res., 24[3] 679-90 (2009).

${ }^{22}$ W. C. Oliver and G. M. Pharr, "Measurement of Hardness and Elastic Modulus by Instrumented Indentation: Advances in Understanding and Refinements to Methodology," J. Mater. Res., 19[1] 3-20 (2004).

${ }^{23}$ M. Miller, C. Bobko, M. Vandamme, and F.-J. Ulm, "Surface Roughness Criteria for Cement Paste nanoindentation," Cem. Concr. Res., 38[4] 467-76 (2008).

${ }^{24}$ C. Famy, A. R. Brough, and H. F. W. Taylor, "The C-S-H Gel of Portland Cement Mortars: Part I. The Interpretation of Energy-Dispersive X-Ray Microanalyses from Scanning Electron Microscopy, with Some Observations on C-S-H, AFm and AFt phase Compositions," Cem. Concr. Res., 33, 1389-98 (2003).

${ }^{25}$ I. G. Richardson and G. W. Groves, "Microstructure and Microanalysis of Hardened Ordinary Portland-Cement Pastes," J. Mater. Sci, 28[1] 265-77 (1993).

${ }^{26}$ A. J. Allen, J. J. Thomas, and H. M. Jennings, "Composition and Density of Nanoscale Calcium-Silicate-Hydrate in Cement," Nat. Mater., 6[4] 311-16 (2007).

${ }^{27}$ J. J. Hughes and P. Trtik, "Micro-Mechanical Properties of Cement Paste Measured by Depth-Sensing Nanoindentation: A Preliminary Correlation of Physical Properties with Phase Type," Mater. Charact., 53[2-4] 223-31 (2004).

${ }^{28}$ A. C. Fischer-Cripps, Nanoindentation. Springer Verlag, New York (2003). 
${ }^{29}$ F. P. Ganneau, F.-J. Ulm, J. Gondzio, and E. J. Garboczi, "An Algorithm for Computing the Compressive Strength of Heterogeneous Cohesive-Frictional Materials_-Application to Cement Paste," Comput. Geotech., 34[4] 25466 (2007).

${ }^{30}$ B. Gathier and F.-J. Ulm, MIT CEE Report R08-01: Multiscale Strength Homogenization-Application to Shale Nanoindentation. MIT, Cambridge, MA (2008).

${ }^{31}$ P. Trtik, J. Dual, B. Muench, and L. Holzer, "Limitation in Obtainable Surface Roughness of Hardened Cement Paste: 'Virtual' Topographic Experiment Based on Focussed Ion Beam Nanotomography Datasets," J. Microsc.Oxf., 232[2] 200-06 (2008).

${ }^{32}$ D. Drouin, A. R. Couture, D. Joly, X. Tasteti, V. Aimezi, and R. Gauvin, "CASINO V2.42—A Fast and Easy-toUse Modeling Tool for Scanning Electron Microscopy and Microanalysis Users," Scanning, 29, 92-101 (2007).

${ }^{33}$ J. I. Goldstein, D. E. Newbury, D. C. Joy, C. E. Lyman, P. Echlin, E. Lifshin, L. Sawyer, and J. R. Michael, Scanning Electron Microscopy and X-ray Microanalysis. Springer Science + Business Media, LLC, New York (2003).

${ }^{34}$ ABAQUS, Dassault Systèmes, Vélizy-Villacoublay, France.

${ }^{35}$ H. Manzano, J. S. Dolado, and A. Ayuela, "Elastic Properties of the Main Species Present in Portland Cement Pastes," Acta Mater., 57[5] 1666-74 (2009).

${ }^{36}$ R. J. M. Pellenq, N. Lequeux, and H. van Damme, "Engineering the Bonding Scheme in C-S-H: The IonoCovalent Framework," Cem. Concr. Res., 38[2] 159-74 (2008).

${ }^{37}$ J. L. Laugesen, "Density Functional Calculations of Elastic Properties of Portlandite, $\mathrm{Ca}(\mathrm{OH})_{2}$, " Cem. Concr. Res., 35, 199-202 (2005).

${ }^{38}$ T. Voigt, Lehrbuch der kristallphysics. Teubner, Berlin (1910).

${ }^{39}$ A. Reuss, "Berechnung des Fliessgrenze von Mischkristallen auf der Prastizitasbedingunug fur Einkristalle," Z. fur angew, Math, Und. Mech, 9, 49-58 (1929).

${ }^{40}$ A. V. Hershey, "The Elasticity of an Isotropic Aggregate of Anisotropic Cubic Crystals," J. Appl. Mechanics, 21, 236 (1954).

${ }^{41}$ L. Dormieux, D. Kondo, and F.-J. Ulm, Microporomechanics. John Wiley and Sons, Ltd., West Sussex, England (2006). 
${ }^{42}$ T. Mori and K. Tanaka, "Average Stress in Matrix and Average Elastic Energy of Materials with Misfitting Inclusions," Acta Metallica, 21[5] 571-74 (1973).

${ }^{43}$ J. Sanahuja, L. Dormieux, and G. Chanvillard, "Modelling Elasticity of a Hydrating Cement Paste," Cem. Concr. Res., 37[10] 1427-39 (2008).

${ }^{44}$ F.-J. Ulm and H. M. Jennings, "Does C-S-H Particle Shape Matter? A Discussion of the Paper 'Modelling Elasticity of a Hydrating Cement Paste', by Julien Sanahuja, Luc Dormieux and Gilles Chanvillard. CCR 37 (2007) 1427-1439," Cem. Concr. Res., 38[8-9] 1126-29 (2008).

${ }^{45}$ R. J.-M. Pellenq, A. Kushima, R. Shahsavari, K. J. Van Vliet, M. J. Buehler, S. Yip, and F.-J. Ulm, "A Realistic Molecular Model of Cement Hydrates," Proc. Natl. Acad. Sci. U. S. A., 106[38] 16102-07 (2009).

${ }^{46}$ R. Shahsavari, M. J. Buehler, R. J.-M. Pellenq, and F.-J. Ulm, "First-Principles Study of Elastic Constants and Interlayer Interactions of Complex Hydrated Oxides: Case Study of Tobermorite and Jennite," J. Am. Ceram. Soc., 92[10] 2323-30 (2009).

${ }^{47}$ G. Constantinides and F.-J. Ulm, "The Effect of Two Types of C-S-H on the Elasticity of Cement-Based Materials: Results from Nanoindentation and Micromechanical Modeling," Cem. Concr. Res., 34[1] 67-80 (2004).

${ }^{48}$ D. Antonangeli, M. Krish, G. Fiquet, J. Badro, D. L. Farber, A. Bossak, and S. Merkel, "Aggregate and SingleCrystalline Elasticity of HCP Cobalt at High Pressure," Phys. Rev. B, 72 134303-1-03-7 (2005).

${ }^{49}$ G. W. Groves, "Microcrystalline Calcium Hydroxide in Portland-Cement Pastes of Low Water-Cement Ratio," Cem. Concr. Res., 11[5-6] 713-18 (1981).

${ }^{50}$ I. G. Richardson, "Tobermorite/Jennite- and Tobermorite/Calcium Hydroxide-Based Models for the Structure of C-S-H: Applicability to Hardened Pastes of Tricalcium Silicate, $\beta$-Dicalcium Silicate, Portland Cement, and Blends of Portland Cement with Blast-Furnace Slag, Metakaolin, or Silica fume," Cem. Concr. Res., 34, 1733-77 (2004).

${ }^{51}$ X. Cong and R. J. Kirkpatrick, "29 Si MAS NMR Study of the Structure of Calcium Silicate Hydrate," Advn. Cem. Based. Mat., 3, 144-56 (1996).

${ }^{52}$ O. Coussy, R. Eymard, and T. Lassabatere, "Constitutive Modeling of Unsaturated Drying Deformable Materials," J. Eng. Mech.-ASCE, 124[6] 658-67 (1998). 
${ }^{53}$ S. Miyazawa and P. J. M. Monteiro, "Volume Change of High-Strength Concrete in Moist Conditions," Cem. Concr. Res., 26[4] 567-72 (1996).

${ }^{54}$ G. W. Scherer, "Stress from Crystallization of Salt," Cem. Concr. Res., 34, 1613-24 (2004).

${ }^{55}$ C. Vernet, "Ultra-Durable Concretes: Structure at the Micro- and Nanoscale," MRS Bulletin [May] 324-27 (2004).

${ }^{56}$ H. F. W. Taylor, "The Reactions of Cement Compounds with Water," Mater. Sci. Monograph. , 28A 39-45 (1985).

${ }^{57}$ J. D. Eshelby, "The Determination of the Elastic Field of an Ellipsoidal Inclusion and Related Problems," Proc. Royal Society, London, A241, 376-96 (1957).

${ }^{58}$ G. Constantinides, Ph.D. thesis, Invariant Mechanical Properties of Calcium-Silicate-Hydrates $(C-S-H)$ in Cement-Based Materials: Instrumented Nanoindentation and Microporomechanical Modeling, Department Civil and Environmental Engineering, MIT, Cambridge, MA (2007).

${ }^{59}$ J. D. Gale, "GULP: A Computer Program for the Symmetry-Adapted Simulation of Solids," J. Chem. Soc.-Faraday Trans., 93[4] 629-37 (1997).

${ }^{60}$ P. J. M. Monteiro and C. T. Chang, "The Elastic Moduli of Calcium Hydroxide," Cem. Concr. Res., 25[8] 1605-09 (1995).

${ }^{61}$ J. J. Beaudoin, "Comparison of Mechanical Properties of Compacted Calcium Hydroxide and Portland Cement Paste Systems," Cem. Concr. Res., 13, 319-24 (1983).

${ }^{62}$ F. H. Wittmann, "Estimation of the Modulus of Elasticity of Calcium Hydroxide," Cem. Concr. Res., 16[6] 971-72 (1986).

${ }^{63}$ P. Acker, "Micromechanical Analysis of Creep and Shrinkage Mechanisms," pp. 15-25. in Creep, Shrinkage, and Durability Mechanics of Concrete and other Quasi-Brittle Materials. Edited by F.-J. Ulm, Z. P. Bazant, and F. H. Wittmann. Elsevier Science Ltd., New York, 2001.

${ }^{64}$ M. Vandamme, F.-J. Ulm, and P. Fonollosa, "The Nanogranular Packing of C-S-H at Substoichiometric Conditions," Cem. Concr. Res., 40[1] 14-26 (2010).

${ }^{65}$ P. Trtik, B. Munch, and P. Lura, "A Critical Examination of Statistical Nanoindentation on Model Materials and Hardened Cement Pastes Based on Virtual Experiments," Cem. Concr. Compos., 31[10] 705-14 (2009).

${ }^{66}$ F.-J. Ulm, M. Vandamme, H. M. Jennings, J. Vanzo, M. Bentivegna, K. J. Krakowiak, G. Constantinides, C. Bobko, and K. J. Van Vliet, "Discussion: Does Microstructure Matter for Statistical Nanoindentation Techniques?," Cem. Concr. Compos., 32[1] 92-99 (2010). 


\section{FIGURE CAPTIONS}

Figure 1. Grid indentation on a heterogeneous system where the probed microvolume (cross-hatched regions below indenter) is either (a) smaller or (b) larger than the characteristic length scale, $D$, of the phase of interest. Symbols are defined in the text.

Figure 2. Comparison of microvolumes probed by nanoindentation and by SEM-EDS. The volume probed by nanoindentation is estimated from the isocontours (black lines) of the normalized local strain energy density calculated by finite element analysis. The volume probed by SEM-EDS is approximated by the zone demarcated by the electron trajectories (blue lines) in the specimen, here calculated by Monte Carlo simulation. In both cases, the interaction volume has a linear dimension of $\approx 1.5-2.0 \mu \mathrm{m}$.

Figure 3. BSE-SEM image of a typical zone of the $w / c=0.20$ hydrated cement paste specimen, showing a grid of 16 indent impressions (triangles, exaggerated in size for visibility). An example of the clinker, inner product (IP), outer product (OP), and defect regions are also shown.

Figure 4. Probability density distributions of (a) indentation modulus $(M)$ and (b) indentation hardness ( $H$ ) for the $w / c=0.20$ hydrated cement paste. The distributions are decomposed by phase: clinker, IP, OP, and pore. The cross-hatch density increases with the stiffness of the phase.

Figure 5. Si/Ca versus total oxide content measured by SEM-EDS. Theoretical oxide totals for clinker phases, portlandite, and $\mathrm{C}-\mathrm{S}-\mathrm{H}$ are shown. Filled points represent microvolumes rich in $\mathrm{C}-\mathrm{S}-\mathrm{H}$ and $\mathrm{CH}$ with oxide totals between $0.68-0.76$. 
Figure 6. $\mathrm{Si} / \mathrm{Ca}$ versus (a) $(\mathrm{Fe}+\mathrm{Al}) / \mathrm{Ca}$ and (b) $\mathrm{S} / \mathrm{Ca}$ obtained by SEM-EDS. Filled points, representing microvolumes containing varying proportions of $\mathrm{C}-\mathrm{S}-\mathrm{H}$ and $\mathrm{CH}$, are those that lie within the dashed curves scattered around the $\mathrm{C}-\mathrm{S}-\mathrm{H} / \mathrm{CH}$ tie-lines in both (a) and (b).

Figure 7. (a) Indentation modulus $M$ and (b) indentation hardness $H$ plotted as a function of the volume fraction of $\mathrm{CH}$ in microvolumes containing $\mathrm{CH}$ and $\mathrm{C}-\mathrm{S}-\mathrm{H}$. The arbitrary trendline in (a) follows the general trend of the $M$-data.

Figure 8. (a) Computed curves for indentation modulus, $M$, versus volume fraction of $\mathrm{CH}, f_{C H}$, calculated for 2 different microstructures where a $\mathrm{C}-\mathrm{S}-\mathrm{H} / \mathrm{CH}$ nancomposite structure is either assumed absent (dashed lines) or present (solid lines) with varying amounts of residual porosity, $\phi_{c r i t}$. (b) Schematic of the double-scale micromechanics model used in the calculation.

Figure 9. Schematic of a hydrated, low $w / c$ cement paste. It is hypothesized that the $\mathrm{C}-\mathrm{S}-\mathrm{H} / \mathrm{CH}$ nanocomposite structure forms in IP regions and in thin films separating cement grains, where there is a local deficiency in water and space (denoted by crosshatched regions). IP (dark), OP (light) and unhydrated cement grains (white) are shown. The influx of $\mathrm{H}^{+}$to the anhydrous clinker core, and the efflux of $\mathrm{Ca}$ and $\mathrm{Si}$ ions to the capillary space are also shown. 


\section{TABLES}

Table 1. Cited and model values for the elastic constants of the $\mathrm{C}-\mathrm{S}-\mathrm{H}$ solid (globule) and of $\mathrm{CH}$. Codes: $\mathrm{N}=$ nanoindentation; $\mathrm{C}=$ measured on pressurized compacts, then extrapolating to zero porosity; $\mathrm{B}=$ brillouin light scattering; EM = force field, energy-minimization; DFT = density function theory.

\begin{tabular}{|c|c|c|}
\hline Property & $\begin{array}{l}\text { Model } \\
\text { values }\end{array}$ & Cited values \\
\hline $\mathrm{E}_{\text {Globule }}$ & 63.5 & $\begin{array}{l}\text { Simulation : } 63.5^{36}(\mathrm{EM}) ; 35.6-56.0^{36}(\mathrm{EM}) ; 51.90^{46}\left(\mathrm{DFT}, 14 \text { A Tobermorite), } 53.55^{46}\right. \\
\text { (DFT, Jennite) } \\
\text { Experiment: } 58-61^{58}(\mathrm{~N} \text {, with } v=0.3) ; 60.0^{2}(\mathrm{~N})\end{array}$ \\
\hline$v_{\text {Globule }}$ & 0.26 & $\begin{array}{l}\text { Simulation: } 0.25-0.26^{36}(\mathrm{EM}) \\
\text { Experiment: } 0.27-0.31^{58}(\mathrm{~N})\end{array}$ \\
\hline $\mathrm{E}_{\mathrm{CH}}$ & 46.0 & $\begin{array}{l}\text { Simulation: } 35.7\left[46.0\left[56.2^{37, a}(\mathrm{DFT}) ; 41.5\left[54.6\left[67.8^{59}(\mathrm{EM}) ; 35.4^{36}(\mathrm{EM})\right.\right.\right.\right. \\
\underline{\text { Experiment: }} 38.9\left[44.9\left[50.9^{59, a}, 39.7\left[40.3\left[44.2^{60}(\mathrm{~B}) ; 35.2^{61}(\mathrm{C}) ; 48^{62}(\mathrm{C}) ; 36.0^{63}\right.\right.\right.\right. \\
(\mathrm{N}) ; 38^{16,47}(\mathrm{~N})\end{array}$ \\
\hline$v_{\mathrm{CH}}$ & 0.26 & $\begin{array}{l}\text { Simulation : } 0.22\left[0.23\left[0.23^{59, a}(\mathrm{EM}) ; 0.24\left[0.26\left[0.28^{37, a} ; 0.31^{35}(\mathrm{EM})\right.\right.\right.\right. \\
\text { Experiment }: 0.32\left[0.33\left[0.35^{59, a} ; 0.30-0.32^{60}(\mathrm{~B})\right.\right.\end{array}$ \\
\hline
\end{tabular}

${ }^{\bar{a}}$ Reported as lower bound, average value, and upper bound, respectively.

Table 2. Atomic density of selected atoms in $\mathrm{C}_{3} \mathrm{~S}$, $\mathrm{HD} \mathrm{C}-\mathrm{S}-\mathrm{H}$, nanoscale $\mathrm{CH}$, and a $\mathrm{C}-\mathrm{S}-\mathrm{H} / \mathrm{CH}$ nanocomposite (with $f_{C H}=0.15$ ).

\begin{tabular}{|c|c|c|c|c|c|c|c|}
\hline & & \multicolumn{4}{|c|}{ Atomic density $\left(1000 \mathrm{~N}_{\mathrm{A}}^{-1}\right)$} & & \\
\hline Phase & Vol. $\left(\mathrm{cm}^{3}\right)$ & $\mathrm{Ca}$ & $\mathrm{Si}$ & $\mathrm{O}$ & $\mathrm{H}$ & $\mathrm{Ca} / \mathrm{Si}$ & $\mathrm{H}_{2} \mathrm{O} / \mathrm{Si}$ \\
\hline (1) $\mathrm{Ca}_{3} \mathrm{SiO}_{5}{ }^{a}$ & 1.00 & 42.2 & 14.1 & 70.4 & 0.0 & 3.0 & 0.0 \\
\hline $\begin{array}{l}\text { (2) } \mathrm{HD} C-\mathrm{S}-\mathrm{H}^{b} \text { (including saturated gel } \\
\text { pores) }\end{array}$ & 1.00 & 18.1 & 10.0 & 70.6 & 64.9 & 1.8 & 3.2 \\
\hline (3) $\mathrm{Ca}(\mathrm{OH})_{2}$ (in nanocomposite) & $(0.15)^{c}$ & 4.5 & 0.0 & 9.1 & 9.1 & - & - \\
\hline (4) $\mathrm{C}-\mathrm{S}-\mathrm{H} / \mathrm{Ca}(\mathrm{OH})_{2}$ nanocomposite & 1.00 & 22.6 & $10.1^{d}$ & $71.4^{e}$ & $57.3^{f}$ & 2.3 & 2.9 \\
\hline (5) Remaining atoms ${ }^{g}$ & - & 19.6 & 4.0 & -1.0 & - & 4.9 & - \\
\hline
\end{tabular}

${ }^{a}$ Assuming $\rho=3.21 \mathrm{~g} \mathrm{~cm}^{-3}$.

${ }^{b}$ Assuming composition, $1.8 \mathrm{CaO} \cdot \mathrm{SiO}_{2} \cdot 3.2 \mathrm{H}_{2} \mathrm{O}, \rho=2.20 \mathrm{~g} \mathrm{~cm}^{-3}$.

${ }^{c}$ Since we assume $\mathrm{CH}$ resides in the pores of $\mathrm{HD} \mathrm{C}-\mathrm{S}-\mathrm{H}$, this volume does not contribute to the apparent volume of the nanocomposite (row 4).

${ }^{d}$ Calculated by adding values from rows (2) and (3)

${ }^{e}$ Calculated as $\rho_{O}^{\text {nanocomposite }}=f_{C-S-H} \frac{\rho_{C-S-H}}{M W_{C-S-H}} f_{O}^{C-S-H}+f_{C-S-H}\left[\frac{\rho_{C H}}{M W_{C H}} f_{O}^{C H}-\frac{\rho_{H 2 O}}{M W_{H 2 O}} f_{O}^{H 2 O}\right]$ where $f_{O}^{j}$ is the oxygen density in phase $j$.

${ }^{f}$ Calculated as $\rho_{o}^{\text {nanocomposite }}=f_{C-S-H} \frac{\rho_{C-S-H}}{M W_{C-S-H}} f_{H}^{C-S-H}+f_{C H}\left[\frac{\rho_{C H}}{M W_{C H}} f_{H}^{C H}-\frac{\rho_{H 2 O}}{M W_{H 2 O}} f_{H}^{H 2 O}\right]$ where $f_{H}^{j}$ is the hydrogen density in phase $j$.

${ }^{g}$ Calculated by subtracting values from rows (1) and (4). 


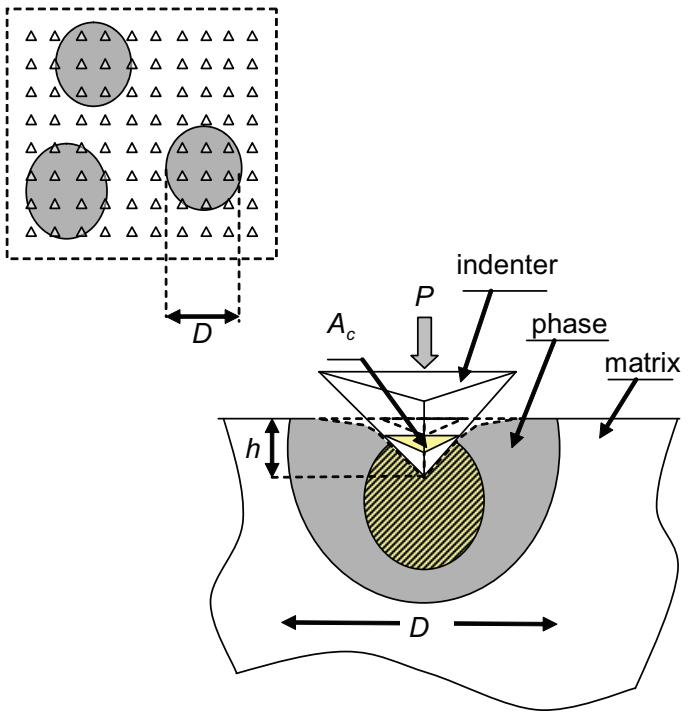


$\Delta \Delta \Delta D_{\Delta \Delta \Delta \Delta \Delta \Delta}$ $\Delta \Delta \Delta \Delta \Delta \Delta Q \Delta \theta^{\Delta}$ $\Delta \Delta \Delta \Delta \Delta \Delta \Delta \Delta \Delta \Delta$ $\Delta \Delta \Delta \nabla \Delta \Delta \Delta \Delta \Delta Q$ $\Delta Q \Delta \Delta \Delta \Delta Q \Delta \Delta \Delta$ $\Delta \Delta \Delta \otimes \Delta \Delta \Delta Q \Delta \Delta$ $\nabla_{\Delta} \Delta \Delta \Delta \Delta \Delta \Delta \Delta \Delta \Delta \Delta$ $\Delta \Delta \Delta \Delta \Delta \Delta \Delta \Delta \Delta \Delta$
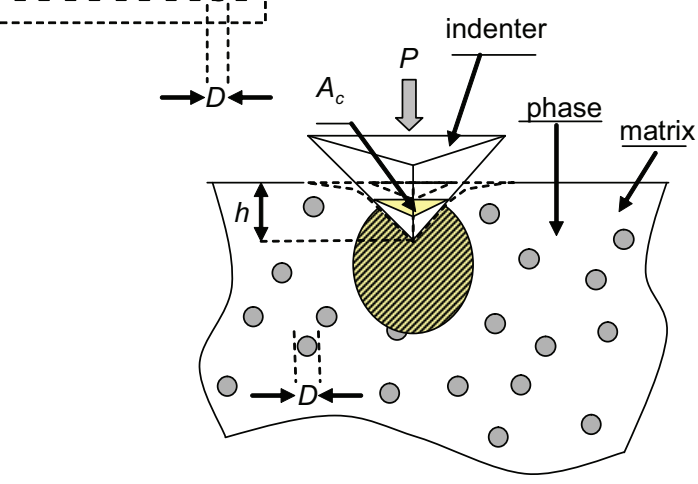


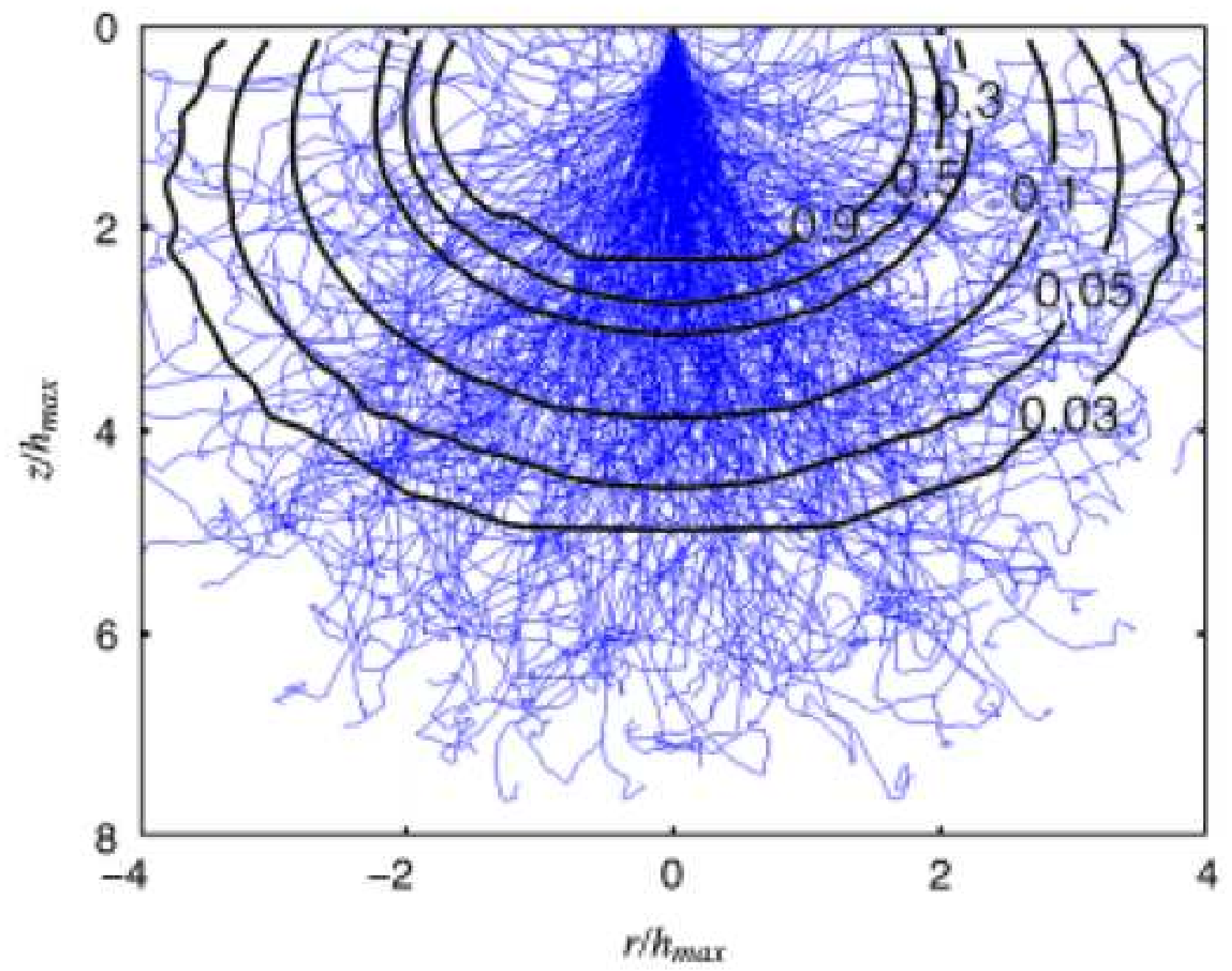




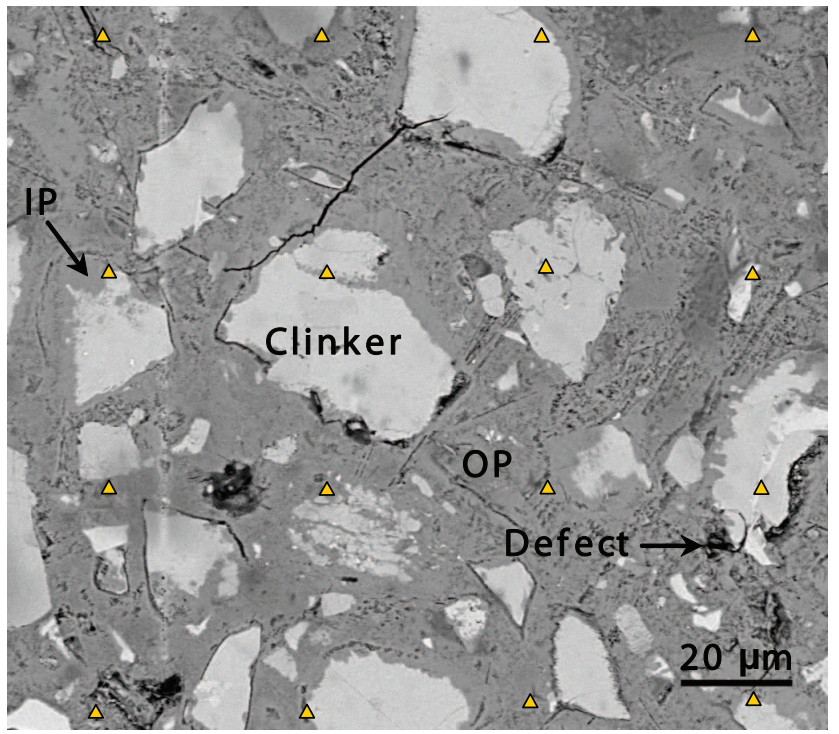




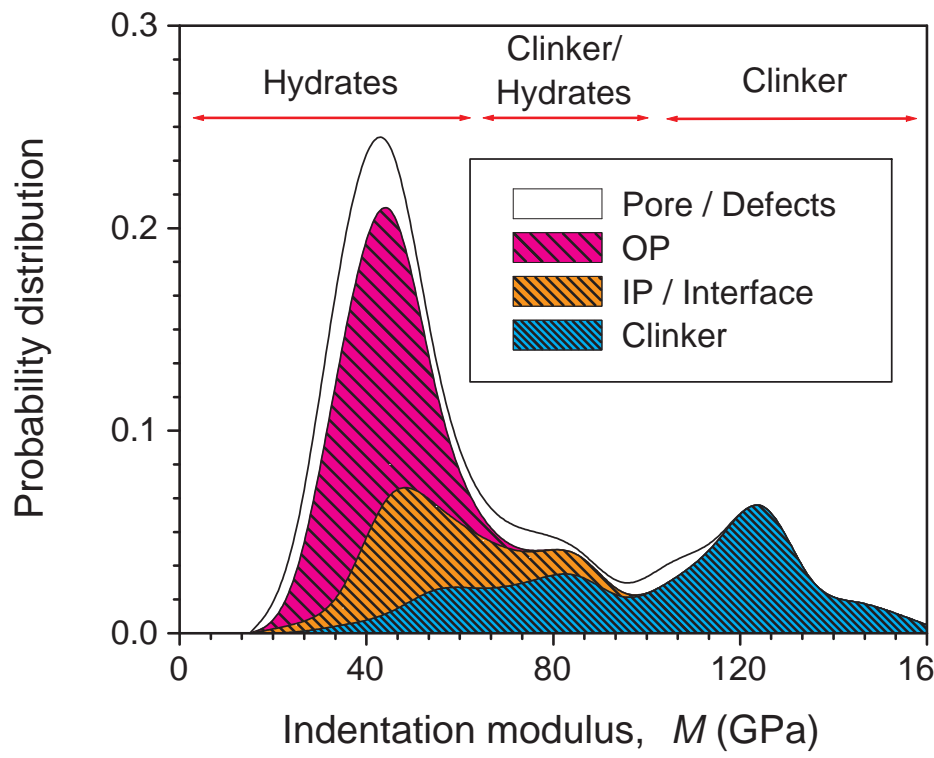




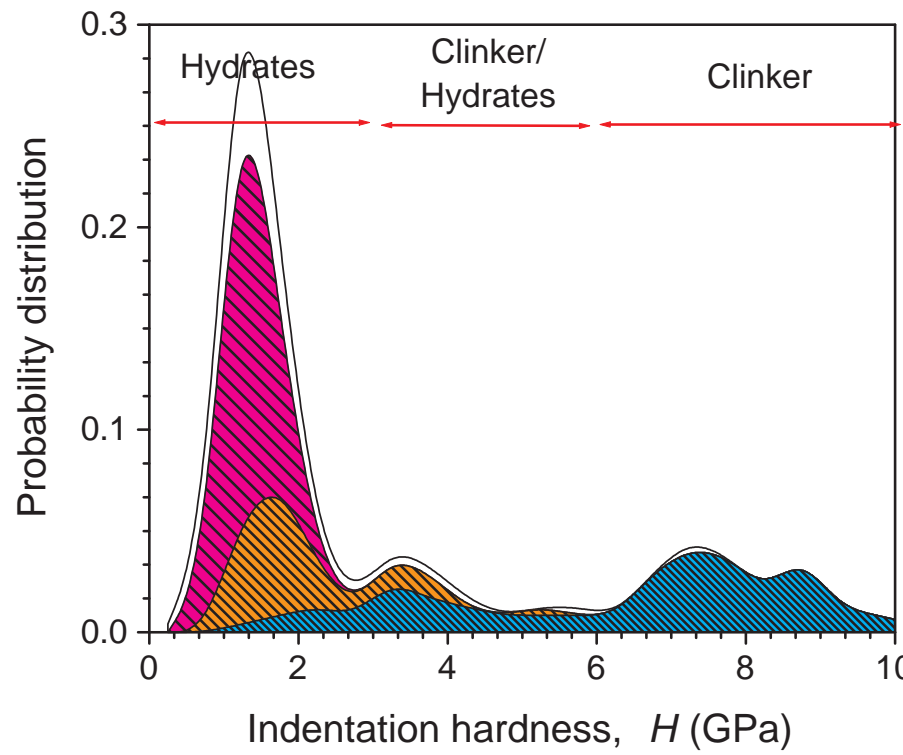




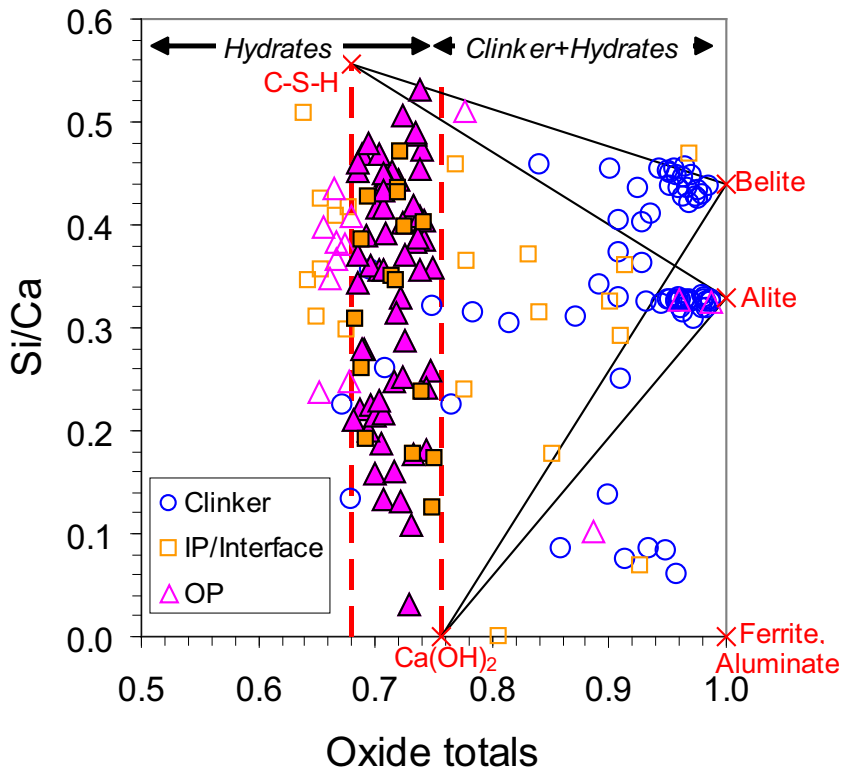




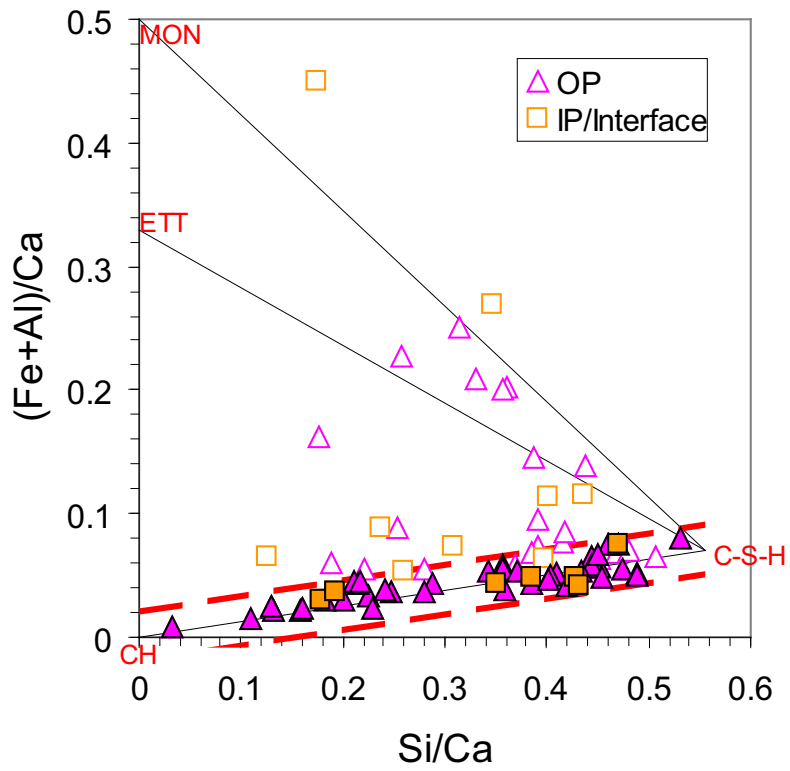




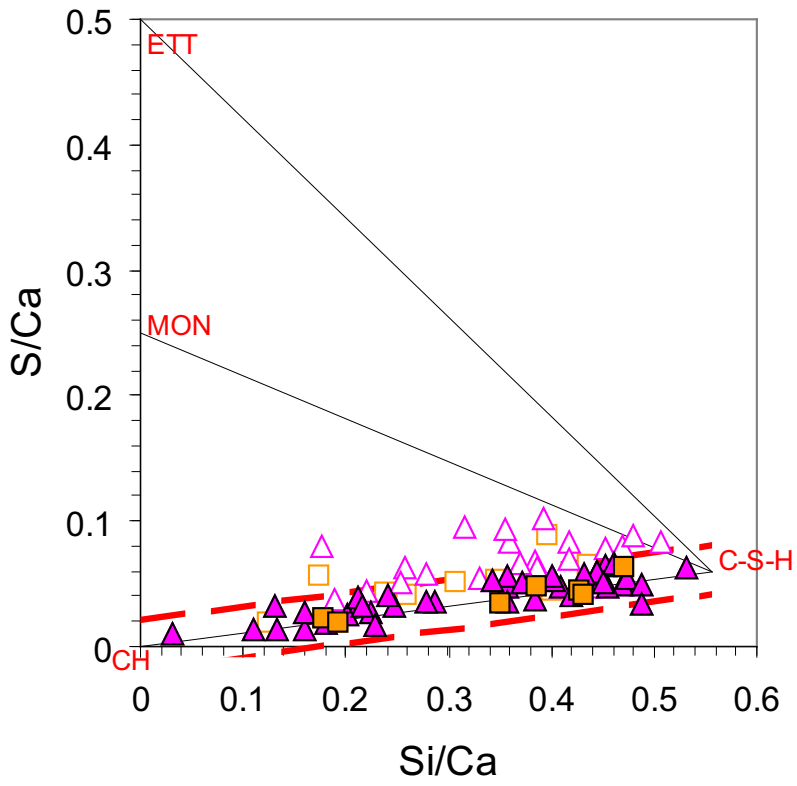




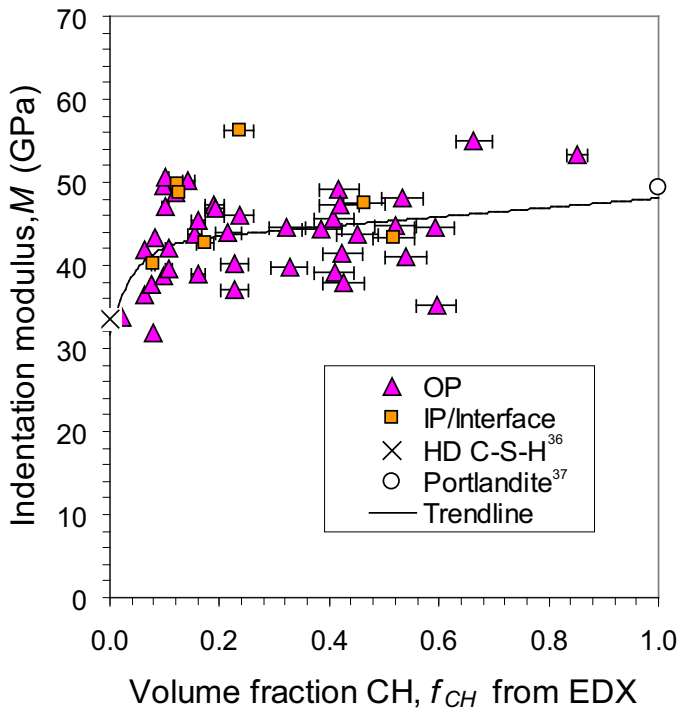




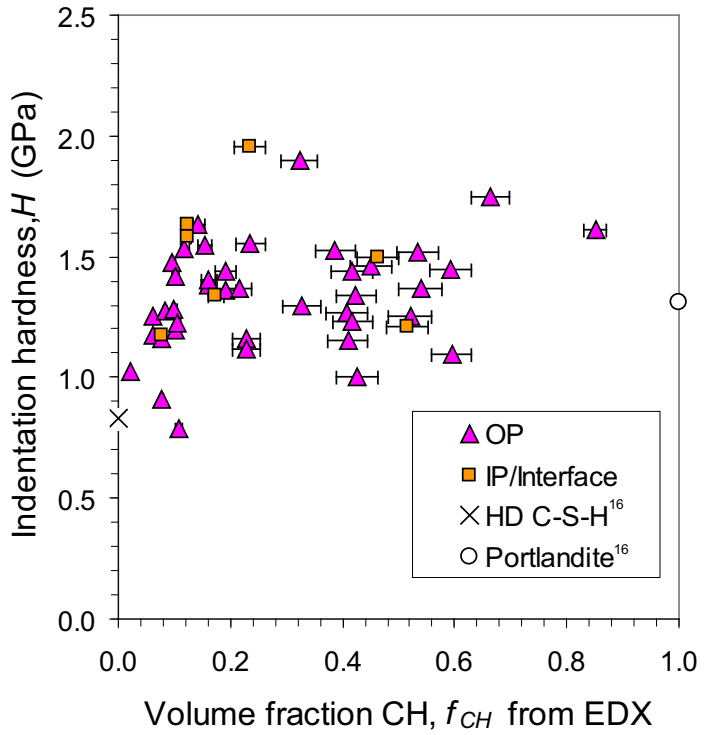




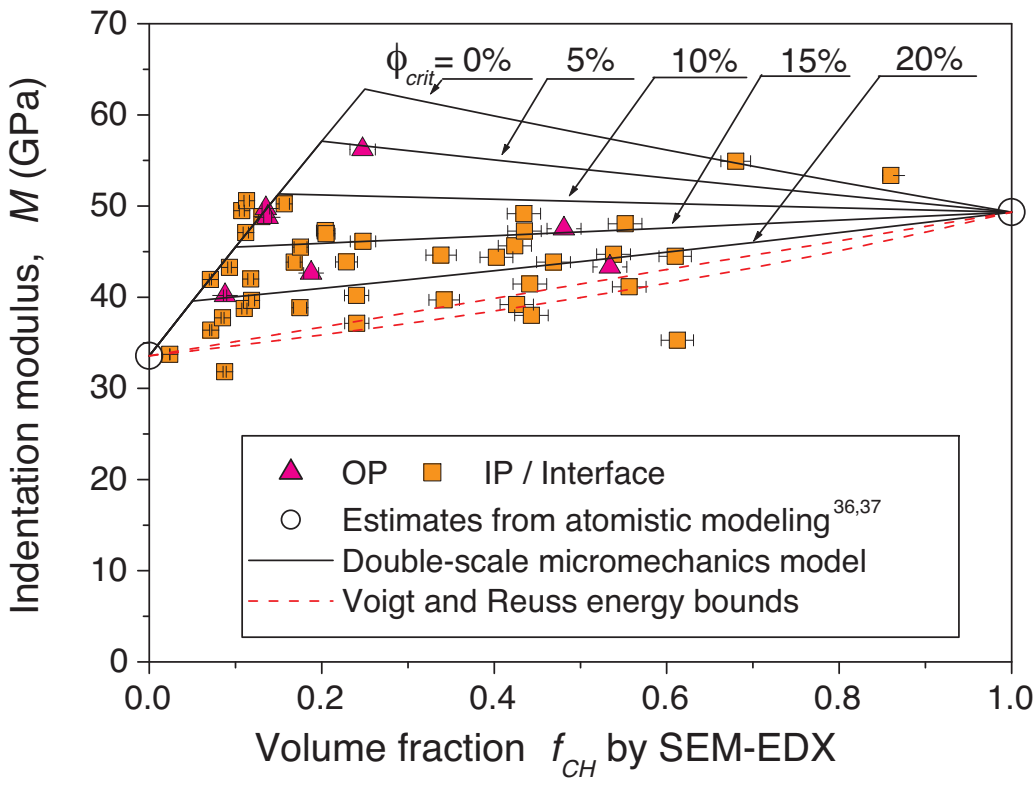




\section{Level 0: Globule}

Level I: Nanoscale $\left(f_{C H} \leq f_{\text {crit }}\right)$

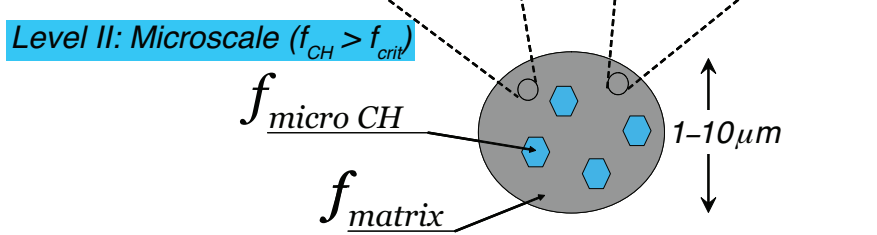




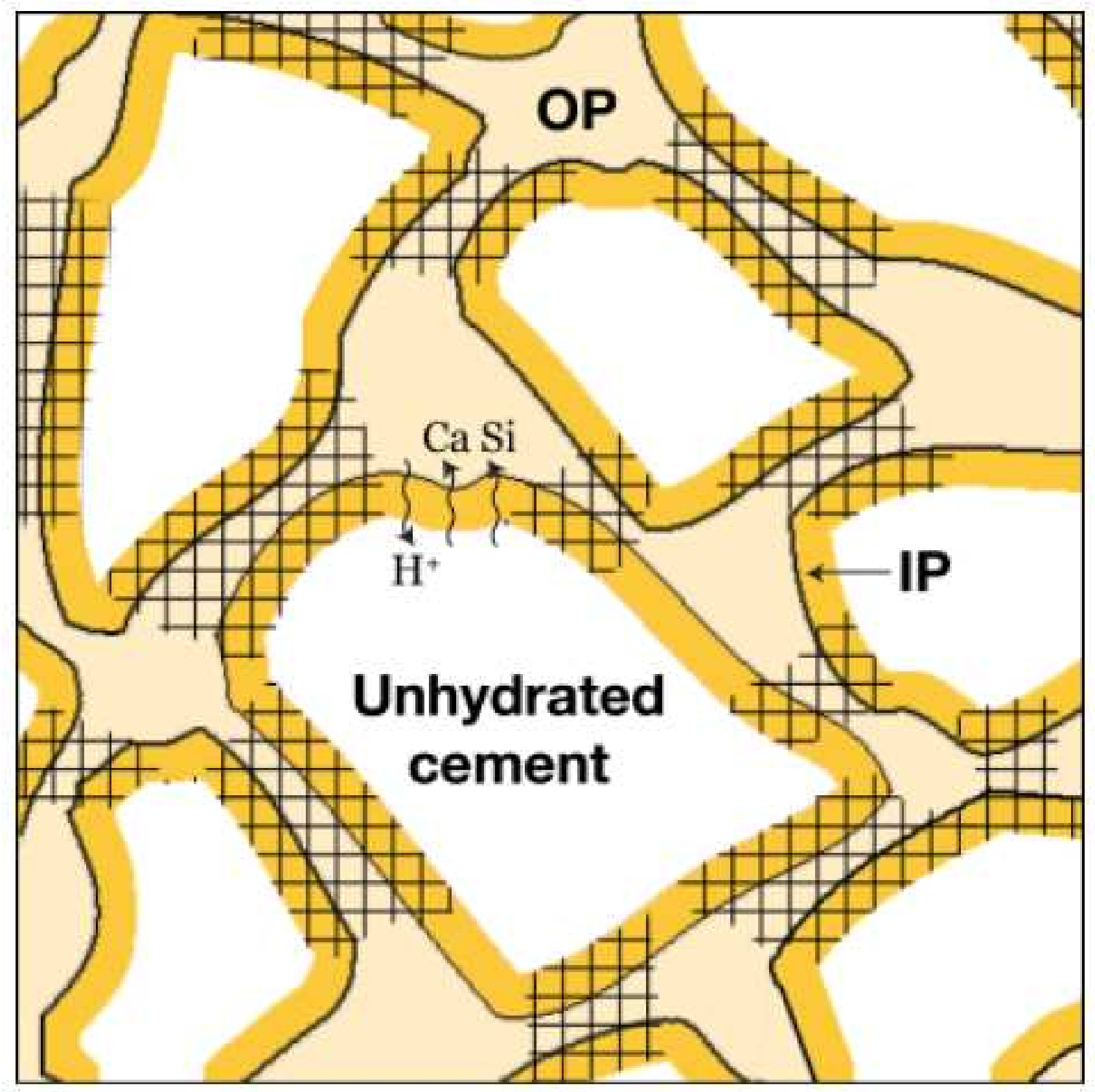

